Working Paper/Document de travail 2014-37

\title{
Predicting Financial Stress Events: A Signal Extraction Approach
}

by Ian Christensen and Fuchun Li 
Bank of Canada Working Paper 2014-37

August 2014

\section{Predicting Financial Stress Events: A Signal Extraction Approach}

by

Ian Christensen ${ }^{1}$ and Fuchun $\mathrm{Li}^{2}$

1Financial Markets Department

${ }^{2}$ Financial Stability Department

Bank of Canada

Ottawa, Ontario, Canada K1A 0G9

chrn@bankofcanada.ca

fuchunli@bankofcanada.ca

Bank of Canada working papers are theoretical or empirical works-in-progress on subjects in economics and finance. The views expressed in this paper are those of the authors. No responsibility for them should be attributed to the Bank of Canada. 


\section{Acknowledgements}

We are grateful to Gabriel Bruneau, James Chapman, Toni Gravelle, Andrew Patton, Tom Roberts, Tatevik Sekhposyan and Norman Swanson, as well as seminar participants at the Bank of Canada 2013 Financial Stability Conference, the 2013 Canadian Econometric Study Group and the 2012 International Symposium on Forecasting for many helpful comments and suggestions, and Hong Xiao for excellent research assistance. 


\begin{abstract}
The objective of this paper is to propose an early warning system that can predict the likelihood of the occurrence of financial stress events within a given period of time. To achieve this goal, the signal extraction approach proposed by Kaminsky, Lizondo and Reinhart (1998) is used to monitor the evolution of a number of economic indicators that tend to exhibit an unusual behaviour in the periods preceding a financial stress event. Based on the individual indicators, we propose three different composite indicators, the summed composite indicator, the extreme composite indicator and the weighted composite indicator. In-sample forecasting results indicate that the three composite indicators are useful tools for predicting financial stress events. The out-of-sample forecasting results suggest that for most countries, including Canada, the weighted composite indicator performs better than the two others across all criteria considered.
\end{abstract}

JEL classification: C14, C4, E37, E47, F36, F37, G01, G17

Bank classification: Financial stability; Econometric and statistical methods

\title{
Résumé
}

Les auteurs proposent un système d'alerte avancée visant à déterminer la probabilité de survenue d'un épisode de tension financière à un moment donné. Pour ce faire, ils s'appuient sur le modèle de détection des signaux élaboré par Kaminsky, Lizondo et Reinhart (1998), qui leur permet de surveiller l'évolution de plusieurs indicateurs économiques susceptibles d'afficher un comportement inhabituel dans les périodes précédant un épisode de tension financière. En combinant certains de ces indicateurs, les auteurs élaborent trois différents indicateurs composites, soit un indicateur composite global, un indicateur composite d'intensité et un indicateur composite pondéré. D’après les résultats de prévision en échantillon, ces trois indicateurs composites se révèlent utiles pour la prédiction des épisodes de tension financière. À la lumière des résultats de prévision hors échantillon, l'indicateur composite pondéré s'avère plus performant que les deux autres pour la plupart des pays (dont le Canada), tous critères d'évaluation confondus.

Classification JEL : C14, C4, E37, E47, F36, F37, G01, G17

Classification de la Banque : Stabilité financière; Méthodes économétriques et statistiques 


\section{Non-technical summary}

The objective of this paper is to propose an early warning system (EWS) that can predict the likelihood of the occurrence of a financial stress event within a given period of time, where a financial stress event is said to occur when a financial stress index rises above 1.5 standard deviations away from the mean. To achieve this goal, the signal extraction approach is used to monitor the evolution of a number of economic indicators that tend to exhibit unusual behaviour in the periods preceding a financial stress event. We construct three different composite indicators, the summed composite indicator, the extreme composite indicator and the weighted composite indicator, by combining the information from all the indicators to assess the likelihood of an upcoming financial stress event.

We evaluate the performance of the three composite indicators in predicting the likelihood of the occurrence of financial stress events within a period of four quarters. In-sample forecasting results for 13 OECD countries suggest that the three composite indicators are useful tools for predicting financial stress events, although none of them outperforms the others across all the criteria considered. Out-of-sample forecasting results indicate that for most of these OECD countries, in-

cluding Canada, the weighted composite indicator performs better than the two others across all the criteria considered.

The EWS model developed in this paper is a useful addition to the toolkit for financial system surveillance models. Further research on EWS models for financial stress events may focus on adding dynamic components to EWS models and, in particular, adding the current endogeneity of economic status. This may be accomplished by utilizing regime-switching models that have been employed successfully in other areas of economic forecasting. 


\section{Introduction}

There is evidence that financial stress may cause severe financial crises and recessions (Bloom (2009), and Borio and Drehman(2009)). It is therefore of crucial importance to detect and to predict potential financial stress for the conduct of economic policy. Given the definition that financial stress is an interruption of the normal functioning of the financial system (ECB, 2009), ${ }^{1}$ the starting point to monitor financial stress is to develop formal measures of financial stress.

In recent years, many studies have been creating a Financial Stress Index (FSI), a continuous measure of the state of stress in the financial system, to examine which economic variables can help predict financial stress for one country or for several countries. For example, the International Monetary Fund (IMF), the Organization of Economic Co-operation and Development (OECD), the Bank for International Settlements (BIS), GoldmanSachs, Bloomberg, Citigroup and the Bank of Canada have developed FSIs to monitor episodes of financial stress. Slinenberg and de Haan (2011) use an FSI for 13 OECD countries to examine whether a list of variables can help predict financial stress. Misina and Tkacz (2009) investigate whether movements in credit and asset prices can help predict financial stress in Canada. However, their work provides only point predictions of future financial stress. Point predictions can, at most, convey some notion of the central tendency of future financial stress, and provide nothing at all about the possible uncertainty of the future financial stress. However, for most decision problems, reliance on point forecasts will not be sufficient and probability forecasts will be needed to provide insights on the likelihood of the occurrence of a financial stress event for a given period of time (Gneitinga and Ranjanb, 2011, and

\footnotetext{
${ }^{1}$ It is difficult to provide a more exact definition, because episodes of financial stress are often different. However, certain key features are frequently associated with financial stress, such as increased uncertainty about the fundamental value of assets, increased uncertainty about the behaviour of other investors, increased asymmetry of information, decreased willingness to hold risky assets and decreased willingness to hold illiquid assets (Hakkio and Keeton, 2009).
} 
the references therein). ${ }^{2}$

Christensen and Li (2013) propose a semiparametric early warning model for financial stress events. Their model performs well in predicting well-known financial stress events. The restriction of their model, however, is that it depends on the assumptions that different countries have the same link function (cumulative distribution function of the residuals), and the data are required to be stationary. These assumptions limit its country coverage and the data used.

The objective of this paper is to propose an early warning system (EWS) that can predict the probability of the occurrence of a financial stress event within a given period of time. To achieve this goal, we use the FSIs proposed by the IMF for developed economies, as the measures of financial stress, to predict the probability of the occurrence of a financial stress event within a given period of time for 13 OECD countries: Belgium, Canada, Denmark, France, Finland, Germany, Italy, Japan, the Netherlands, Sweden, Switzerland, the United Kingdom and the United States. The signal extraction approach proposed by Kaminsky, Lizondo and Reinhart (1998)(KLR) is used to monitor the evolution of a number of economic indicators that tend to exhibit unusual behaviour in the period preceding a financial stress event. Most of the indicators used in this paper come from the indicators reported in Demirgüç-Kunt and Detragiache (1998), Kaminsky (1998), and Davis and Karim (2008), but for different countries and different time spans. ${ }^{3}$ These indicators are chosen based on theoretical considerations and their availability on a quarterly basis. In particular, we add a financial contagion indicator into the set of indicators to capture the possible contagion effect, because a financial stress event is more likely to spread to a country that is competing and trading

\footnotetext{
${ }^{2}$ The detailed definition of a financial stress event will be given in Section 2.

${ }^{3}$ Demirgüç-Kunt and Detragiache (1998), Kaminsky (1998), and Davis and Karim (2008) predict financial crises using economic and financial variables. Their procedure runs into difficulties when applied to countries where financial crises are rare or non-existent events. A typical example is Canada, which has not experienced any "twin crises" (banking and currency crises) since the beginning of its sample in 1883, and has experienced only four currency crises since 1945. The absence of financial crises, however, does not imply that a country has not been subjected to financial stress in the past. To circumvent this problem, this paper focuses on predicting the likelihood of the occurrence of a financial stress event.
} 
with countries that have been experiencing a financial stress event. Twelve indicators are included in our model: real GDP growth rate, exchange rate, real short-term interest rate, inflation, ratio of M2 to foreign exchange rate, return on house price index, growth rate of private credit, ratio of bank reserves to bank assets, ratio of current account to GDP, return on stock market index, indicator of financial contagion and the three-quarter moving average of FSI.

Given the individual indicators, we propose three different composite indicators, namely, the summed composite indicator, the extreme composite indicator and the weighted composite indicator, which are used to predict the probability of the occurrence of a financial stress event. We evaluate in-sample and out-of-sample performance of the three composite models. In-sample forecasting results suggest that the three composite indicators are useful tools for predicting financial stress events, although none of them outperforms others across all the criteria considered. Out-of sample forecasting results indicate that for most of the countries, including Canada, the weighted composite indicator performs better than the two others across all the criteria considered.

The paper is organized as follows: Section 2 presents the definition of a financial stress event and introduces how to use the proposed signal extraction approach to predict the likelihood of the occurrence of financial stress events for a given period of time. Section 3 evaluates the performance of our early warning system. Section 4 concludes.

\section{Model Specification}

The design of an early warning system for financial stress events requires consideration of the scope of the model (country coverage, choice of indicators and time dimensions), the definition of a financial stress event, and the econometric model. In this paper, we adopt the econometric model used by KLR (1998) to predict the probability of the occurrence of a financial stress event within 
a given period of time.

\subsection{The Definition of a Financial Stress Event}

In general, financial stress is unobservable, but some key features are frequently associated with an increased degree of perceived risk and uncertainty. To capture these features of financial stress, the IMF constructed an FSI for developed economics. The FSI is a variance-weighted average of three subindexes associated with the banking, securities and foreign exchange markets. All components in the three subindexes are originally in monthly frequency. The FSI is constructed by taking the average of the components after adjusting for the sample mean and standardizing by the sample standard deviation. Finally, it is converted into a quarterly frequency by taking the average of the monthly data. ${ }^{4}$ In this paper, we use the FSIs proposed by the IMF as the measures of financial stress for 13 OECD countries: Belgium, Canada, Denmark, Finland, France, Germany, Italy, Japan, the Netherlands, Sweden, Switzerland, the United Kingdom and the United States.

The signal extraction approach used in this paper involves monitoring the evolution of a number of economic indicators. When one of these indicators deviates from its " normal " behaviour, this is taken as a warning signal about a possible financial stress event within a given period of time. To make the approach operational, we need to define what is a financial stress event.

As a first step, for country $j$, we define a financial stress event as the event when the financial stress index rises above an extreme value,

$$
h f s_{j, t}= \begin{cases}1 & \text { if } F S I_{t}>\mu_{F S I}+k \sigma_{F S I} \\ 0 & \text { otherwise }\end{cases}
$$

where $\mu_{F S I}$ and $\sigma_{F S I}$ are the sample mean of FSI and the sample standard deviation. To identify financial stress events, Illing and Liu (2006) use $k=2$ in equation (1), while Cardarelli et al.

\footnotetext{
${ }^{4}$ The FSI comprises seven variables: the banking-sector beta, the TED spread, term spreads, stock market returns, time-varying stock market return volatility, sovereign debt spread and exchange market volatility. The details of the components of the index are explained in Cardarelli, Elekdag and Lall (2009).
} 
(2009) use $k=1$ in equation (1). In this paper, we use $k=1.5$ to identify the financial stress events. Although the choice of $k=1.5$ as a threshold is somewhat arbitrary, the cataloguing of crises obtained by this choice tends to follow closely the chronology of financial market stress described in the literature. In particular, another reason that we chose $k=1.5$ standard deviation is that it yields a reasonable number of observations for estimating the probabilities of the occurrence that a financial stress event happens. ${ }^{5}$

Since the values of FSI are very volatile, in terms of its persistence, implying that frequently switching between a financial stress event and a normal state of financial stress is implausible, we construct a quarterly data-based EWS model for financial stress events. As well, some important indicators, for example, GDP data and the current account/GDP, are available only at quarterly frequencies. We therefore use quarterly observations of the FSI.

The next crucial question is to define the signalling horizon or the window of a financial stress event. The objective of our EWS is not to predict the exact timing of a financial stress event, but to predict whether a financial stress event occurs within a specific time horizon. Our approach consists of transforming the variable $h f s_{j, t}$ into a forward-looking variable $Y_{j, t}$ which is defined as follows:

$$
Y_{j, t}= \begin{cases}1 & \text { if } \exists k=1, \ldots, 4 \text { s.t. } h f s_{j, t+k}=1 \\ 0 & \text { otherwise. }\end{cases}
$$

In other words, our model attempts to predict whether a financial stress event will occur during a particular period of time, in this case, in the upcoming four quarters. Choosing the length of this period requires a balance between two opposite requirements. On the one hand, the indicators tend

\footnotetext{
${ }^{5}$ Using a threshold vector autoregression (TVAR) model with four variables (GDP growth rate, inflation, financial stress index, and interest rate) in which the FSI is chosen as the threshold variable, we find that the economy can be characterized by regimes of low and high financial stress, and that the high financial stress regime has a higher inflation, FSI, interest rate and lower output growth than the low financial stress regime. In-sample and out-of sample forecasting performance indicates that the EWS model based on equation (1) firmly outperforms the EWS in which the financial stress events are defined from the threshold value in the TVAR model.
} 
to issue signals when a financial stress event comes. Therefore, the closer the financial stress event is, the more reliably it can be anticipated. On the other hand, from a policy-maker perspective, it is desirable to have an indication of financial vulnerabilities as early as possible in order to be able to take pre-emptive policy measures. Although some early warning models for financial crises use even longer time horizons, the four-quarter horizon can provide a good trade-off between these two issues. 6

Figures 1-4 display the FSIs for the 13 countries for the sample period starting from 1981Q2 to 2010Q2. The horizontal line is the threshold described in equation (1), and the shaded regions represent the financial crises. When the FSI exceeds this threshold value, it indicates the occurrence of a financial stress event. The higher the values of the index, the higher the financial stress. It is of interest to note that even though the component parts of the FSI are based on individual data and the thresholds vary across countries, the peaks of the index largely coincide with episodes of financial stress events that are international in nature; for example, the stock market crash in October 1987, the long-term capital management (LTCM) crisis in 1998, the subprime crisis starting in the third quarter 2007, etc. This is not surprising, given that these economies are well-integrated internationally. As such, they are not insulated from international financial developments. ${ }^{7}$

\subsection{Individual Indicators}

We follow the signal extraction approach by assessing the behaviour of single indicators prior to and during a financial stress event. The logic is that if aberrant behaviour of an indicator can be quantitatively defined, then whenever that indicator moves from tranquil to abnormal activity, a

\footnotetext{
${ }^{6}$ A robustness check shows that our empirical models presented below do not change much when choosing sixquarter or eight-quarter horizons.

${ }^{7}$ Between 1981Q2 to 2010Q2, there were 146 financial stress events among the 13 countries. In particular, the number of financial stress events for Canada, the United States, the countries in the European area, and Japan, is $11,11,115$ and 9, respectively.
} 
financial stress event is forewarned. At time $t$, an indicator $j$ is denoted by $X_{t}^{j}$ and the threshold for this indicator is denoted as $X^{* j}$. At time $t$, a signal variable relating to $j$ is denoted by $S_{t}^{j}$. This is constructed to be a binary variable, where $S_{t}^{j}=\{0,1\}$. If the indicator crosses the threshold $X^{* j}$, a signal is issued and $S_{t}^{j}=1$. This happens when $\left\{S_{t}^{j}=1\right\}=\left\{\left|X_{t}^{j}\right|>\left|X^{* j}\right|\right\}$. If the indicator remains within its threshold boundary, it behaves normally and does not issue a signal, thus $\left\{S_{t}^{j}=0\right\}=$ $\left\{\left|X_{t}^{j}\right|<\left|X^{* j}\right|\right\}$.

Most of indicators used in this paper come from the indicators reported in Demirgüç-Kunt and Detragiache (1998), Kaminsky (1998), and Davis and Karim (2008). We add a financial contagion indicator to the set of indicators to capture the possible contagion effect, because a financial stress event is more likely to spread to a country that is competing and trading with countries that have been experiencing a financial stress event. We include 12 indicators in our model: real GDP growth rate, short-term interest rate, inflation, exchange rate, ratio of current account to GDP (current account/GDP), growth rate of real private credit, ratio of bank reserves to bank assets (reserve/bank asset), ratio of M2 to foreign exchange reserve (M2/foreign exchange reserve), return on house price index, return on stock market index, three-quarter moving average of the FSI, and financial contagion indicator. The financial contagion indicator for a country is measured as the sum of the FSIs multiplied with the correlation coefficient of a country-pair stock market return. ${ }^{8}$

Cross-country data are used to derive a threshold for each indicator, which distinguishes between normal and aberrant behaviour. Notice that the directional sign may vary depending on whether the indicator in question has an upper or lower bound. Hence, the indicators and thresholds are expressed in absolute terms. Therefore, for a time series of observations for a given

\footnotetext{
${ }^{8}$ For each country $i$, we define its financial contagion indicator as $\sum_{j \neq i} F S_{i} \operatorname{correl}\left(r_{i}, r_{j}\right)$, where $r_{i}$ and $r_{j}$ are the returns of stock market indexes for country $i$ and country $j$, and correl $\left(r_{i}, r_{j}\right)$ is the correction coefficient between $r_{i}$ and $r_{j}$.
} 
country $j$, we can obtain a binary time series of signal or no-signal observations. This series is then checked against actual events to construct a measure of predictive accuracy. There are four possible scenarios:

$\begin{array}{lll} & \text { Financial stress event } & \text { No financial stress event } \\ \text { Signal issued } & A & B \\ \text { No signal issued } & C & D\end{array}$

In this matrix, $A$ is the number of quarters in which the model issued a correct signal, $B$ is the number of quarters in which the model issued a wrong signal, $C$ is the number of quarters in which the model failed to issue a signal, and $D$ is the number of quarters in which the model refrained from issuing a signal. If an EWS model issues a signal in a quarter that is followed by a financial stress event (within the next four quarters), then $A>0$ and $C=0$. If it does not issue a signal in the quarter that is not be followed by a financial stress event (within the next four quarters), then $B=0$ and $D>0$. A perfect model would produce only $A$ and $D$, with $B=0$ and $C=0$.

The key to the signal extraction approach is to choose the threshold level that would strike a balance between the risk of having many bad signals and the risk of missing many financial stress events. The optimal thresholds are calculated to minimize the noise-to-signal ratio, which implies minimizing the ratio $[B /(B+D)] /[A /(A+C)]$. In particular, if $B=0$, the noise-to-signal ratio would be zero, which is the "perfect" indicator. If $A=0$, then the noise-to-signal ratio is infinity. To obtain the threshold, a grid search is performed: the noise-to-signal ratio is calculated for a range of potential threshold values and the value that minimizes the noise-to-signal ratio is the threshold chosen for the indicator.

It should be noted that a threshold is defined relative to the percentile of the distribution of the indicator by country. For example, if the optimal threshold is the 10th percentile, then one 
determines the value of the indicator at the 10th percentile of its distribution for each country. The actual value varies across countries, but the percentile is the same. Other information in addition to the noise-to-signal ratio can be derived from the matrix.

Table 1 provides information on the indicators used in this paper. The first column shows the category headings and the second column provides the name of the indicator. The third column reports whether the upper or lower value of each indicator would signal that the economy is vulnerable to a financial stress event. The fourth column briefly summarizes the economic rationale for using the indicator.

Using data from 1981Q2 to 2007Q3 to estimate threshold percentiles, Table 2 presents information on the performance of individual indicators. The second column displays the size of the critical region where the noise-to-signal ratio is at a minimum, which is determined using a grid search over the range from 0.1 to 0.2 percentile for lower tail risk and from 0.8 to 0.9 percentile for upper tail risk. The critical region translates into examining extreme values at the tail of the distribution. The third column shows the number of good signals issued by the indicator, expressed as a percentage of the number of quarters in which good signals could have been issued $A /(A+C)$. In terms of the results in the third column, the three-quarter moving average of the FSI issues the highest percentage of possible good signals, while the contagion indicator issues the second highest percentage of possible good signals, and return on stock market index issues the lowest percentage of possible good signals. The fourth column measures the performance of individual indicators regarding sending bad signals, expressed as a percentage of the number of quarters in which bad signals could have been issued $B /(B+D)$. Other things being equal, the lower the number in this column is, the better the indicator's performance. The three-quarter moving average of the FSI shows the best performance, while the growth rate of private credit and liquidity show the 
poorest performance. The fifth column reports the noise-to-signal ratio, calculated as the ratio of the false signals as a portion of the quarters in which there is no financial stress event $B /(B+D)$ relative to the good signals, the proportion of quarters in which there was a financial stress event $A /(A+C)$. The best indicator based on the lowest noise-to-signal ratio is the three-quarter moving average of the FSI. The ratios that are equal to or greater than one imply that the indicator is not very good at signalling a financial stress event. We find that the liquidity indicator yields a noise-to-signal ratio above one. Thus, the indicator of liquidity is removed from the list of indicators in the signal extraction approach. We also interpret the results regarding the noisiness of the indicators in another way, by comparing the probability of a financial stress event conditional on a signal from the indicator, $A /(A+B)$, with the unconditional probability of a financial stress event, $(A+C) /(A+B+C+D)$. If the indicator has useful information, the conditional probability would be higher than the unconditional one. The sixth column reports the conditional probabilities, while the seventh column presents the difference between the conditional and unconditional probabilities for each of indicators. It is clear that the set of indicators for which the conditional probability of a financial stress event is lower than the unconditional probability is the same as the one for which the noise-to-signal ratio is higher than one. The analysis of the individual indicators suggests that these indicators, except for liquidity, can indeed be useful and do significantly better than guesses based on the unconditional probability of financial stress events.

\subsection{Composite Indicators and Predicting Financial Stress Events}

One straightforward way of capturing the fragility of the economy prior to a financial stress event is to keep track of the number of signals being issued in the different sectors of the economy. We can combine the information provided by all the indicators to assess the likelihood of an upcoming financial stress event. In this paper, we consider three composite indicators that are considered by 
KLR (1998) for predicting the probabilities of a currency crisis.

In principle, the larger the number of signals from different sectors of the economy, the higher the odds of a financial stress event. The first composite indicator is $I_{t}^{1}$, which is defined as

$$
I_{t}^{1}=\sum_{j=1}^{n} S_{t}^{j}
$$

where $S_{t}^{j}$ is equal to one if indicator $j$ crosses the threshold in period $t$ and zero otherwise.

$I_{t}^{1}$ does not discriminate between the signal provided by a mild anomalous behaviour of an indicator and the signal provided by an extreme aberrant behaviour of that indicator. However, an extreme aberrant behaviour of an indicator may signal a financial stress event with more accuracy than just a mild behaviour. To account for this information, the second composite indicator, $I_{t}^{2}$, accounts for the intensity of the signal of each univariate indicator, which is defined as

$$
I_{t}^{2}=\sum_{j=1}^{n}\left(S M_{t}^{j}+2 S E_{t}^{j}\right),
$$

where $S M_{t}^{j}=1$ if $\left|\bar{X}_{m}^{j}\right|<\left|X_{t}^{j}\right|<\left|\bar{X}_{e}^{j}\right|$, and it will issue an extreme signal, $S E_{t}^{j}=1$ when $\left|X_{t}^{j}\right|>\left|\bar{X}_{e}^{j}\right|$, where $\left|\bar{X}_{m}^{j}\right|$ is the mild threshold and $\left|\bar{X}_{e}^{j}\right|$ is the extreme threshold. We choose the extreme threshold at 0.05 percentile for lower tail risk, and 0.95 percentile for upper tail risk.

The two composite indicators do not fully use the information provided by the univariate indicators because they do not account for the different forecasting accuracy of each indicator. One possible way of combining this information is to weight the signals of different indicators by the inverse of their noise-to-signal ratio. The third composite indicator is defined as

$$
I_{t}^{3}=\sum_{j=1}^{n} \frac{S_{t}^{j}}{\omega^{j}}
$$

where $\omega^{j}$ is the noise-to-signal ratio of indicator $j$.

While the composite indicators described above may be informative, we cannot infer from their values the likelihood that a country will experience a financial stress event. In order to predict the 
likelihood of occurrence of a financial stress event, for each value of the composite index we need to build up an associated probability of occurrence of a financial stress event within a given period of time. For the composite index $I_{t}^{k}, k=1,2$ and 3 , the conditional probability of a financial stress event can be defined as the relative frequency of the occurrence of a financial stress event within a window of $h$ quarters when the composite indicator lies in a certain interval $\left(I_{i}^{k}, I_{j}^{k}\right]$,

$$
\begin{aligned}
& P\left[C_{t, t+h} \mid I_{i}^{k}<I_{t}^{k} \leq I_{j}^{k}\right]= \\
& \frac{\text { Quarters with } I_{i}^{k}<I_{t}^{k} \leq I_{j}^{k} \text { and a financial stress event within the next four quarters }}{\text { Quarters with } I_{i}^{k}<I_{t}^{k} \leq I_{j}^{k}},
\end{aligned}
$$

where $P$ denotes probability, $C_{t, t+h}$ is the occurrence of a financial stress event in the interval $[t, t+h), h$ is the window of a financial stress event, $I_{t}^{k}$ is the value of the composite indicator at time $t$, the subscripts $I_{i}^{k}$ and $I_{j}^{k}$ denote upper and lower bound for the interval $\left(I_{i}^{k}, I_{j}^{k}\right] . P\left[C_{t, t+h} \mid I_{i}^{k}<\right.$ $\left.I_{t}^{k} \leq I_{j}^{k}\right]$ denotes the probability that a financial stress event will occur within $h$ quarters at time $t$, given that the composite indicator $I_{t}^{k}$ falls within the interval $\left(I_{i}^{k}, I_{j}^{k}\right]$. In this paper, we take the forecast horizon $h$ as four quarters.

Using data from 1981Q2 to 2007Q3, Table 3 reports the conditional probabilities of occurrence of a financial stress event that are associated with different values of the three composite indicators when they fall into different intervals. Unlike composite I and composite II, the values that composite III can take are uncountable. We use the method proposed by Diebold and Rudebusch (1989) to choose the intervals. Letting $M$ represent the in-sample maximum value, we evenly divide the interval $(0, M]$ into non-overlapping subintervals $\left\{\Gamma_{l}\right\}_{l=1}^{L}$. Let $P_{l}$ be the predicted probability of a financial stress event within four quarters, conditional on information that the composite $I_{t}^{k}$ falls into the interval $\Gamma_{l}$ at time $t$, for $t=1, \ldots, T$, and $\left\{R_{t}\right\}_{t=1}^{L}$ be the time series of realizations of financial stress events. $R_{t}=1$ if a financial stress event occurs between $t$ and $t+h ; R_{t}=0$ otherwise. 
We define

$$
Q_{\Gamma_{l}}^{k}=\sum_{t=1}^{T} I_{\left(I_{t}^{k} \in \Gamma_{l}\right)}\left(P_{l}-R_{t}\right)^{2},
$$

and

$$
Q_{\left\{\Gamma_{l}\right\}_{l=1}^{L}}^{k}=\sum_{l=1}^{L} Q_{\Gamma_{l}}^{k},
$$

where $I_{(\cdot)}$ is an indicator function. We choose $L^{*}$ such that $\left\{\Gamma_{l}\right\}_{l=1}^{L^{*}}$ minimizes $Q_{\left\{\Gamma_{l}\right\}_{l=1}^{T}}^{k}$, where we stipulate $L=50$ and $L^{*} \leq L=50$. Given data from 1981Q2 to 2007Q3, we have $M=23.2$ for composite indicator $I_{t}^{3}$. Using equation (8), we have $L^{*}=7$, and $\Gamma_{1}=(0,3.3], \Gamma_{2}=(3.3,6.6], \ldots, \Gamma_{7}=$ $(19.8,23.2]$. Given $\Gamma_{1}, \ldots, \Gamma_{7}$, the last column in Table 3 reports the probability that indicator $I_{t}^{3}$ falls into each of these intervals.

As shown in Table 3, in general, the probability of occurrence of a financial stress event increases as the values of composite indicators rise. Using the information on the quarterly values of the composite indicators, and the conditional probabilities of financial stress events in Table 3 , we can construct series of probabilities of financial stress events for the 13 countries, both in-sample and out-of-sample.

\section{Predictive Ability}

We divide our data into two subsamples. The first subsample, from 1981Q2 to 2007Q3, is used to build up the model parameters, such as the composite indicators; the second subsample, from 2007Q4 to 20110Q2, is used to evaluate out-of-sample performance of early warning for financial stress events. ${ }^{9}$

\footnotetext{
${ }^{9}$ For a robustness check, we also use the data from 1981Q3 to 2006Q4 to estimate the model parameters. The results are qualitatively similar to those for observations from 1981Q2 to 2007Q3. In practice, to provide reliable out-of-sample early warning results for financial stress events, we need a sufficient number of observations to estimate parameters.
} 
The probability forecast evaluation is based on five different criteria: the signal to noise ratio; the probability of financial stress events correctly called; the probability of false alarms in total alarms; the conditional probability of financial stress events given an alarm; and the conditional probability of financial stress given no alarm. The probability of financial stress events correctly called is defined as the percentage of the number of quarters in which a signal is followed by at least one financial stress event within the next four quarters $(A /(A+C))$. The probability of false alarms in total alarms is defined as the percentage of the number of quarters in which a signal is not followed by at least one financial stress event within the next four quarters $(B /(A+B))$. The conditional probability of financial stress events given an alarm is defined as the percentage of the number of quarters in which a signal is followed by at least one financial stress event within the next four quarters $(A /(A+B))$. The conditional probability of financial stress given no alarm is defined as the percentage of the number of quarters in which a signal is not issued, but at least one financial stress event occurs within the next four quarters $(C /(C+D))$.

Corresponding to the value of $I_{t}^{k}$ at time $t(k=1,2$ and 3$)$, there is a probability that predicts the likelihood of a financial stress event occuring within four quarters. The higher the probability threshold for calling a financial stress event, the higher the probability of Type I errors (failure to call a financial stress event). The lower the probability threshold chosen, the more signals sent, and the higher the probability of Type II errors (false alarms). For each country, we obtain the optimal threshold probability at which the noise-to-signal ratio, defined as $[B /(B+D)] /[A /(A+C)]$, is minimized. ${ }^{10}$

\footnotetext{
${ }^{10}$ An efficient warning system should minimize false alarms, since issuing a warning will lead to some sort of preventive actions, which are usually costly. For example, the decision-maker may invest in gathering further information, such as holding discussions with senior mangers of the financial markets, bank supervisory agencies, or other market participants. Alternatively, the decision-maker may use the monitoring system to decide whether to take preventive policy measures, such as tightening prudential capital or liquidity requirements for banks or reducing interest rates to ease pressures on bank balance sheets. In contrast, raising the probability threshold reduces the number of wrong signals, but at the expense of increasing the number of missing signals of financial stress events.
} 
To obtain the "optimal" threshold probability, a grid search is performed over the range of potential threshold probabilities, from 0.15 to 0.50 . The probability value where the noise-to-signal ratio is at a minimum is chosen and is called the cut-off probability. Using the information on the quarterly values of the three composite indicators and the conditional probabilities in Table 3 , we can construct series of forecasted probabilities of financial stress events for the 13 countries. If the forecast probability of a financial stress event exceeds the cut-off probability, the early warning system will issue a warning. Otherwise, the early warning system will not issue a warning signal.

Tables 4-16 report the in-sample and out-of-sample forecasting accuracy of the three composite indicators for each of the 13 countries. The top panel in each table evaluates the in-sample forecasting probabilities of the three composite indicators. The signal-to-noise ratios for all 13 countries are higher than one, indicating that the in-sample forecasting performance of the three composite indicators is better than random guesses. Consequently, the three composite indicators are useful tools for predicting financial stress events, although none of them outperforms the others across all the criteria considered.

Particularly, for all countries with the exception of the Belgium, Germany and France, composite indicator III performs better than both composite indicator I and composite indicator II in terms of the probability of financial stress events correctly called, as well as the conditional probability of financial stress given no alarm. These results indicate that while the simple summation of individual indicators and the extreme weighted composite indicator provide some aggregate information, they may not fully utilize the information obtained from analysis of the performance of individual indicators, because they do not account for the different forecasting accuracy of each indicator. In contrast, composite III puts more weight on the signals issued by indicators shown to have more reliable forecasting performance in terms of the ability to accurately call financial stress events and 
non-financial stress events.

In-sample predictive ability is important and can reveal useful information, but there is no guarantee that a model that fits historical data well will also perform well out-of-sample. It is important to note that the value of the EWS for financial stress events lies in its ability to provide policy-maker with early warning of impending financial stress events, therefore it depends on its out-of-sample predictive ability.

The bottom panels in Tables 4-16 report the out-of-sample forecasting accuracy of the three composite indicators. For Finland, France and Sweden, since the number of quarters in which the three composite indicators issued a good signal is zero, the signal-to-noise ratios and the probability of financial stress events correctly called are either zero $(A=0)$ or not available $(A /(A+C)=0 / 0)$, and all signals issued by the three composite indicators are bad signals because all alarms are false alarms, suggesting that the three composite indicators are not helpful in predicting financial stress events for the three countries. For all of remaining countries countries, the out-of-sample values of the signal-noise ratios for composite I and composite III are greater than one, suggesting composite I and composite III provide helpful information for predicting financial stress events. Composite II provides useful information for early warning of financial stress events for all countries with the exception of Finland, France, Italy, Japan, Sweden and the United Kingdom.

For Belgium, Canada, Denmark, Switzerland, the United Kingdom, Italy and the United States, composite III consistently outperforms composite I and performs better or equal to composite II across all the criteria considered. Notably, for Canada, composite III performs better than both composite I and composite II. For example, moving either composite I or composite II to composite III increases the probability of financial stress events correctly called from 0.38 to 0.88 , while reducing the false alarm from 0.25 to 0.12 . Similarly, the conditional probability of experiencing a 
financial stress event when an alarm was issued rises from 0.75 to 0.88 , and the conditional probability of having a financial stress event given no alarm decreases from 0.63 to 0.25 . Overall, the out-of-sample forecasting results suggest that for most of countries, including Canada, composite indicator III performs better than the two others across all the criteria considered.

Figures 5-8 plot the probabilities from composite indicator III for the 13 countries. The shaded regions represent the financial stress events identified by equation (1) for individual countries. A noticeable feature of these graphs is that the probabilities for all countries, with the exception of Finland, are quite a bit higher than their cut-off probabilities during most of the subprime crisis. This result is consistent with the fact that all countries, with the exception of Finland and France, experienced financial stress events at the time of the subprime crisis.

More generally, the forecasted probabilities from composite indicator III often rise during financial stress events rather than in advance. However, it is notable that these forecasted probabilities rise in Sweden and Finland before the financial stress events they experienced in the early 1990s. In future work, we will extend the forecast horizon to two years to put more emphasis on indicators that give earlier signals. In addition, we plan to investigate which indicators best predict the start of a stress episode. 


\section{Conclusion}

This paper proposes an early warning system that can predict the likelihood of the occurrence of financial stress events within a given period of time. To achieve this goal, the signal extraction approach is used to monitor the evolution of a number of economic indicators that tend to exhibit unusual behaviour in the periods preceding a financial stress event. We construct three different composite indicators, the summed composite indicator, the extreme composite indicator and the weighted composite indicator, by combining the information from all the indicators to assess the likelihood of an upcoming financial stress event.

We evaluate in-sample and out-of-sample performance of the three composite models for predicting financial stress events. In-sample forecasting results suggest that the three composite indicators are useful tools for predicting financial stress events, although none of them outperforms the others across all the criteria considered. Out-of-sample forecasting results indicate that for most of countries, including Canada, the weighted composite indicator correctly predicts most financial stress events during the subprime crisis period and performs better than the two others across all the criteria considered.

Further research on EWS models for financial stress events may focus on adding dynamic components to the EWS models and, in particular, on studying the effects of economic status on the forecasted probabilities. This may be accomplished, for instance, by utilizing regime-switching models that have been employed successfully in other areas of economic forecasting. 
Table 1: Interpretation of Indicators

\begin{tabular}{|c|c|c|c|}
\hline Category & Indicator & Risk tail & Comments \\
\hline \multirow{4}{*}{$\begin{array}{l}\text { Macroeconomic } \\
\text { indicator }\end{array}$} & Real GDP growth & Lower tail & Economic recession often precedes crises. \\
\hline & Exchange rate & Upper tail & $\begin{array}{l}\text { Financial crises could be driven by excessive } \\
\text { foreign exchange risk exposure. }\end{array}$ \\
\hline & $\begin{array}{l}\text { Real short-term interest } \\
\text { rate }\end{array}$ & Upper tail & $\begin{array}{l}\text { High real short-term interest rates affect bank } \\
\text { balance sheets adversely and are often associ- } \\
\text { ated with capital outflows. }\end{array}$ \\
\hline & Inflation & Upper tail & $\begin{array}{l}\text { Inflation is likely to be associated with high } \\
\text { nominal interest rates and it may proxy macroe- } \\
\text { conomic mismanagement and adversely affect } \\
\text { the financial sector through various channels. }\end{array}$ \\
\hline \multirow[t]{8}{*}{$\begin{array}{l}\text { Financial indi- } \\
\text { cator }\end{array}$} & $\begin{array}{l}\text { M2/foreign exchange re- } \\
\text { serve }\end{array}$ & Upper tail & $\begin{array}{l}\text { Expansionary monetary policy and/or a sharp } \\
\text { decline in reserves are associated with the on- } \\
\text { set of a crisis. }\end{array}$ \\
\hline & Bank reserve/bank asset & Lower tail & $\begin{array}{l}\text { Adverse macroeconomic shocks should be less } \\
\text { likely to lead to crises when the banking sector } \\
\text { is liquid. We use the ratio to capture liquidity. }\end{array}$ \\
\hline & $\begin{array}{l}\text { Growth rate of real pri- } \\
\text { vate credit }\end{array}$ & Upper tail & $\begin{array}{l}\text { Credit expands prior to a crisis and contracts af- } \\
\text { ter a crisis. }\end{array}$ \\
\hline & $\begin{array}{l}\text { Return on stock market } \\
\text { index }\end{array}$ & Lower tail & $\begin{array}{l}\text { Stock market downturns are associated with } \\
\text { crises. }\end{array}$ \\
\hline & $\begin{array}{l}\text { Return on house price in- } \\
\text { dex }\end{array}$ & Lower tail & $\begin{array}{l}\text { House price index downturns are associated } \\
\text { with crises. }\end{array}$ \\
\hline & Current account/GDP & Lower tail & $\begin{array}{l}\text { Large current deficits are associated with imbal- } \\
\text { ances that may lead to a crisis. }\end{array}$ \\
\hline & Contagion indicator & Upper tail & $\begin{array}{l}\text { Large values of a contagion indicator are } \\
\text { associated with financial stress events. }\end{array}$ \\
\hline & $\begin{array}{l}\text { Three-quarter moving } \\
\text { average of FSI }\end{array}$ & Upper tail & $\begin{array}{l}\text { A high value of the three-quarter moving } \\
\text { average of the FSI predicts a financial stress } \\
\text { event. }\end{array}$ \\
\hline
\end{tabular}


Table 2: Performance of Indicators in the Signal Extraction Approach

\begin{tabular}{|c|c|c|c|c|c|c|}
\hline Indicator & $\begin{array}{l}\text { Threshold } \\
\text { percentile }\end{array}$ & $\frac{A}{(A+C)}$ & $\frac{B}{(B+D)}$ & $\begin{array}{l}\text { Noise/signal } \\
\text { ratio }\end{array}$ & $P[$ crisis $\mid$ signals $]$ & $\begin{array}{l}P[\text { crisis } \mid \text { signals }] \\
-P[\text { crisis }]\end{array}$ \\
\hline Real GDP growth & 0.11 & 0.18 & 0.09 & 0.49 & 0.30 & 0.13 \\
\hline Exchange rate & 0.90 & 0.16 & 0.09 & 0.52 & 0.28 & 0.11 \\
\hline Real interest rate & 0.90 & 0.20 & 0.08 & 0.40 & 0.34 & 0.17 \\
\hline Inflation & 0.89 & 0.24 & 0.08 & 0.35 & 0.37 & 0.20 \\
\hline M2/foreign exchange reserve & 0.85 & 0.18 & 0.14 & 0.79 & 0.21 & 0.04 \\
\hline Bank reserve/bank asset & 0.22 & 0.20 & 0.23 & 1.13 & 0.16 & -0.02 \\
\hline $\begin{array}{l}\text { Growth rate of } \\
\text { private credit }\end{array}$ & 0.77 & 0.24 & 0.23 & 0.95 & 0.18 & 0.01 \\
\hline Return on stock market index & 0.11 & 0.15 & 0.09 & 0.63 & 0.25 & 0.08 \\
\hline Return on house price index & 0.11 & 0.17 & 0.09 & 0.52 & 0.28 & 0.11 \\
\hline Current account/GDP & 0.10 & 0.24 & 0.07 & 0.28 & 0.42 & 0.25 \\
\hline Contagion indicator & 0.84 & 0.33 & 0.12 & 0.37 & 0.36 & 0.19 \\
\hline $\begin{array}{l}\text { 3-quarter moving } \\
\text { average of FSI }\end{array}$ & 0.90 & 0.36 & 0.04 & 0.12 & 0.63 & 0.46 \\
\hline $\begin{array}{l}\text { The Estimation period is from } \\
\text { percentile, which minimizes th } \\
\text { and is used to determine the " } \\
\text { signals(measuredas as } \mathrm{B} /(\mathrm{B}+\mathrm{C} \\
\text { percentage of the signals issue } \\
\text { four quarters. } P[\text { crisis }] \text { is defin }\end{array}$ & $\begin{array}{l}881 \mathrm{Q} 2 \mathrm{t} \\
\text { noise to } \\
\text { imal th } \\
\text { to good } \\
\text { by the in }\end{array}$ & $\begin{array}{l}070 \\
\text { al r } \\
\text { old" } \\
\text { nals } \\
\text { ator }\end{array}$ & $\begin{array}{l}\text { ing } \\
\text { is } 0 \\
\text { ise- }\end{array}$ & $\begin{array}{l}\text { from the } 1 \\
\text { ned by usii } \\
\text { gnal ratio i } \\
\text { s } A /(A+C) \\
\text { wed by at }\end{array}$ & $\begin{array}{l}\text { OECD countri } \\
\text { a grid search o } \\
\text { defined as the } \mathrm{r} \\
P[\text { crisis } \mid \text { signal } \\
\text { ast one crisis } \mathrm{W}\end{array}$ & $\begin{array}{l}\text { Threshold } \\
\text { ar the risk tail, } \\
\text { io of false } \\
\text { is defined as the } \\
\text { hin the subsequent } \\
B+C+D \text { ). }\end{array}$ \\
\hline
\end{tabular}


Table 3: Conditional Probabilities of a Financial Stress Event Associated with Composite Indicators

\begin{tabular}{|c|c|c|c|c|c|}
\hline \multicolumn{2}{|c|}{ Composite Indicator I $\left(I_{t}^{1}\right)$} & \multicolumn{2}{|c|}{ Composite Indicator II $\left(I_{t}^{2}\right)$} & \multicolumn{2}{|c|}{ Composite Indicator III $\left(I_{t}^{3}\right)$} \\
\hline Value & Probability & Value & Probability & Value & Probability \\
\hline 1 & 0.11 & 1 & 0.10 & $(0,3.3]$ & 0.10 \\
\hline 2 & 0.14 & 2 & 0.13 & $(3.3,6.6]$ & 0.13 \\
\hline 3 & 0.23 & 3 & 0.15 & $(6.6,9.9]$ & 0.36 \\
\hline 4 & 0.46 & 4 & 0.24 & $(9.9,13.2]$ & 0.41 \\
\hline 5 & 0.69 & 5 & 0.26 & $(13.2,16.5]$ & 0.56 \\
\hline 6 & 0.75 & 6 & 0.56 & $(16.5,19.8]$ & 0.79 \\
\hline \multirow[t]{4}{*}{7} & 0.88 & 7 & 0.50 & $(19.8,23.2]$ & 0.93 \\
\hline & & 8 & 0.71 & & \\
\hline & & 9 & 0.90 & & \\
\hline & & Over 10 & 1.00 & & \\
\hline
\end{tabular}

The probability is calculated by equation (6). Composite Indicator I is defined as $I_{t}^{1}=\sum_{i=1}^{n} S_{t}^{i}$, where $S_{t}^{i}$ is equal to one if indicator $i$ crosses the threshold in period $t$ and zero otherwise.

Composite Indicator II is defined as $I_{t}^{2}=\sum_{i=1}^{n}\left(S M T_{t}^{i}+2 S E T_{t}^{i}\right)$, where $S M T_{t}^{i}=1$, when indicator $i$ is between the mild threshold and the extreme threshold, and zero otherwise; $S E T_{t}^{i}=1$, when indicator $i$ crosses the extreme threshold and zero otherwise. The extreme threshold is defined at 0.05 percentile for lower tail risk and at 0.95 percentile for upper tail risk. Composite Indicator III is defined as $I_{t}^{3}=\sum_{j=1}^{n} \frac{S_{t}^{j}}{\omega^{j}}$, where $\omega^{j}$ is the noise-to-signal ratio of variable $j$. 


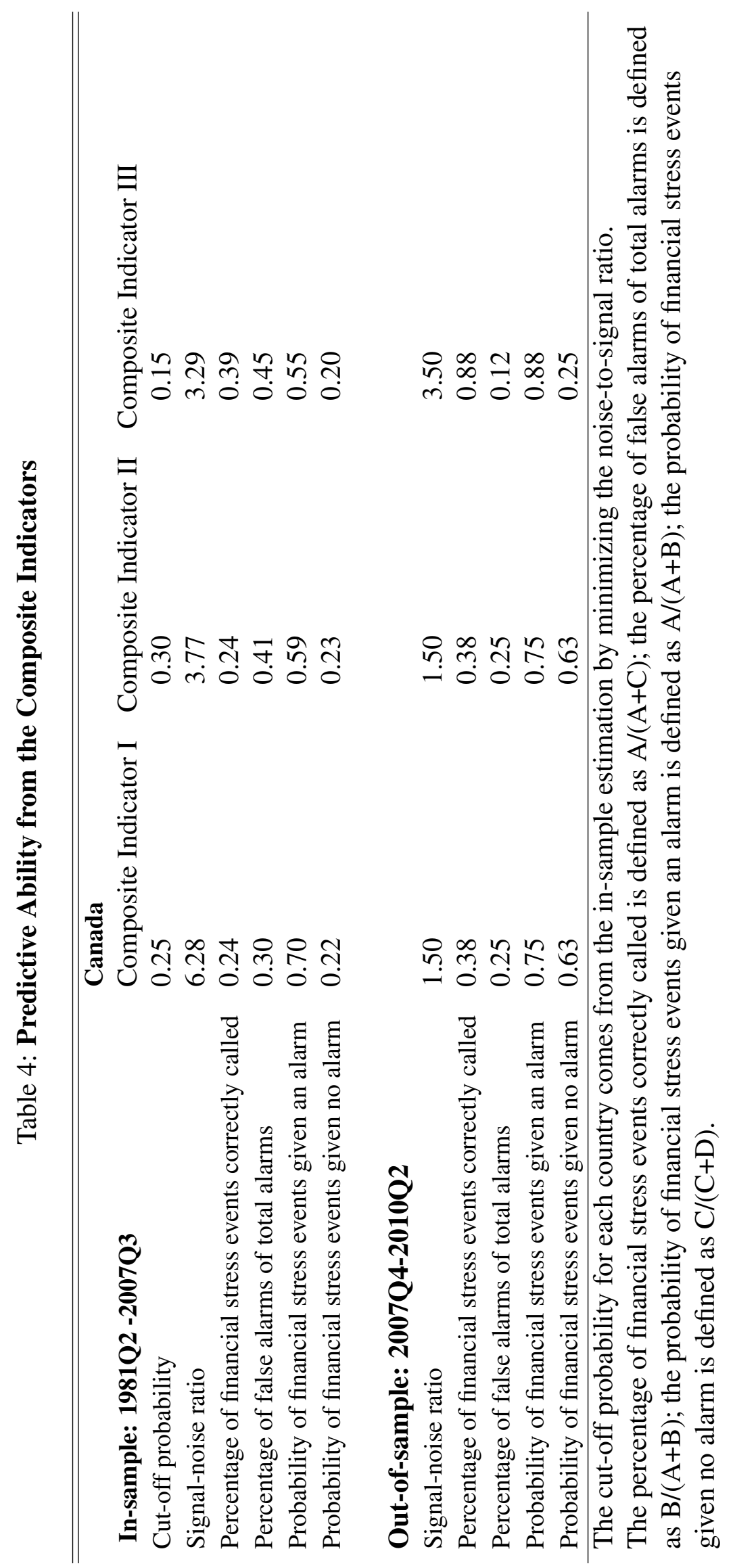




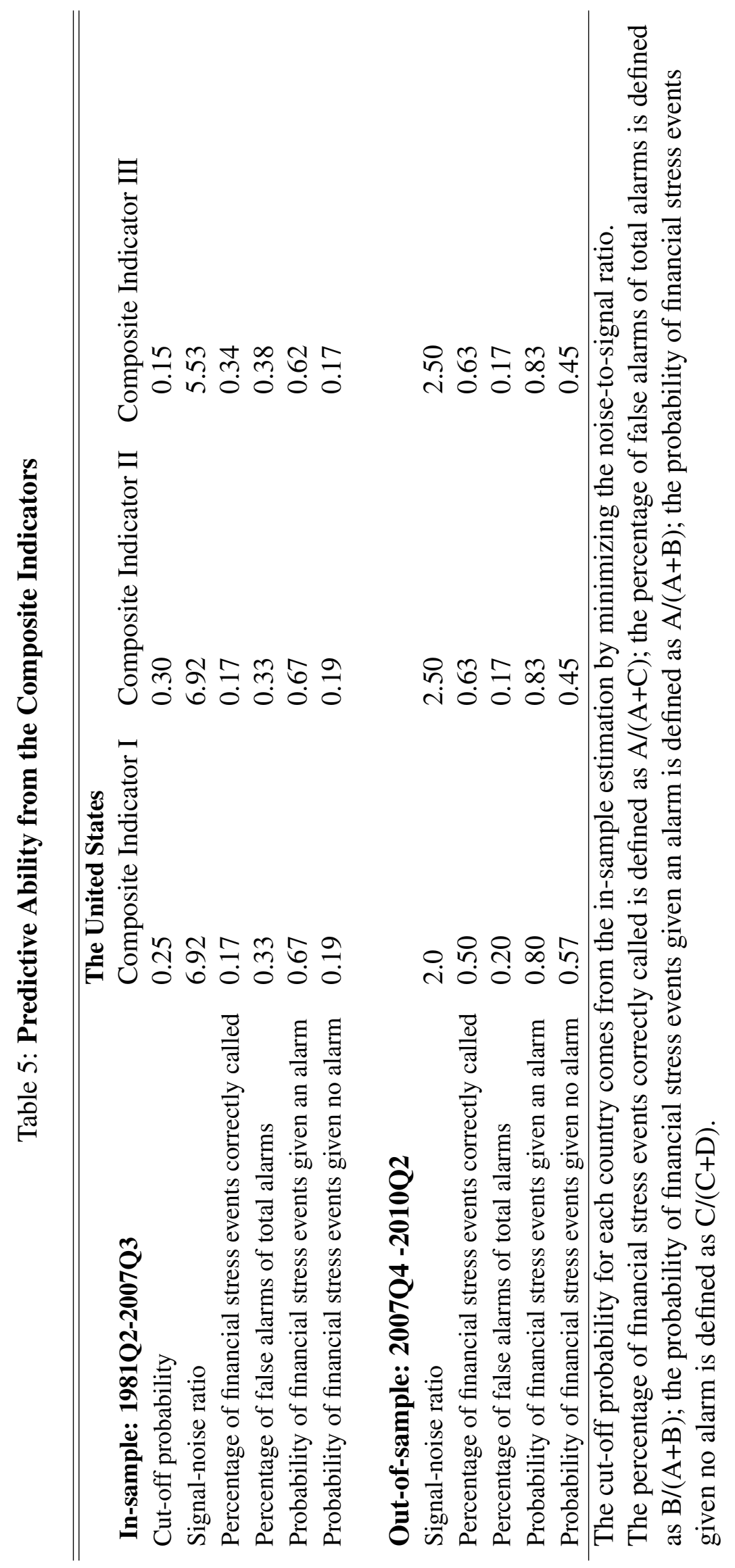




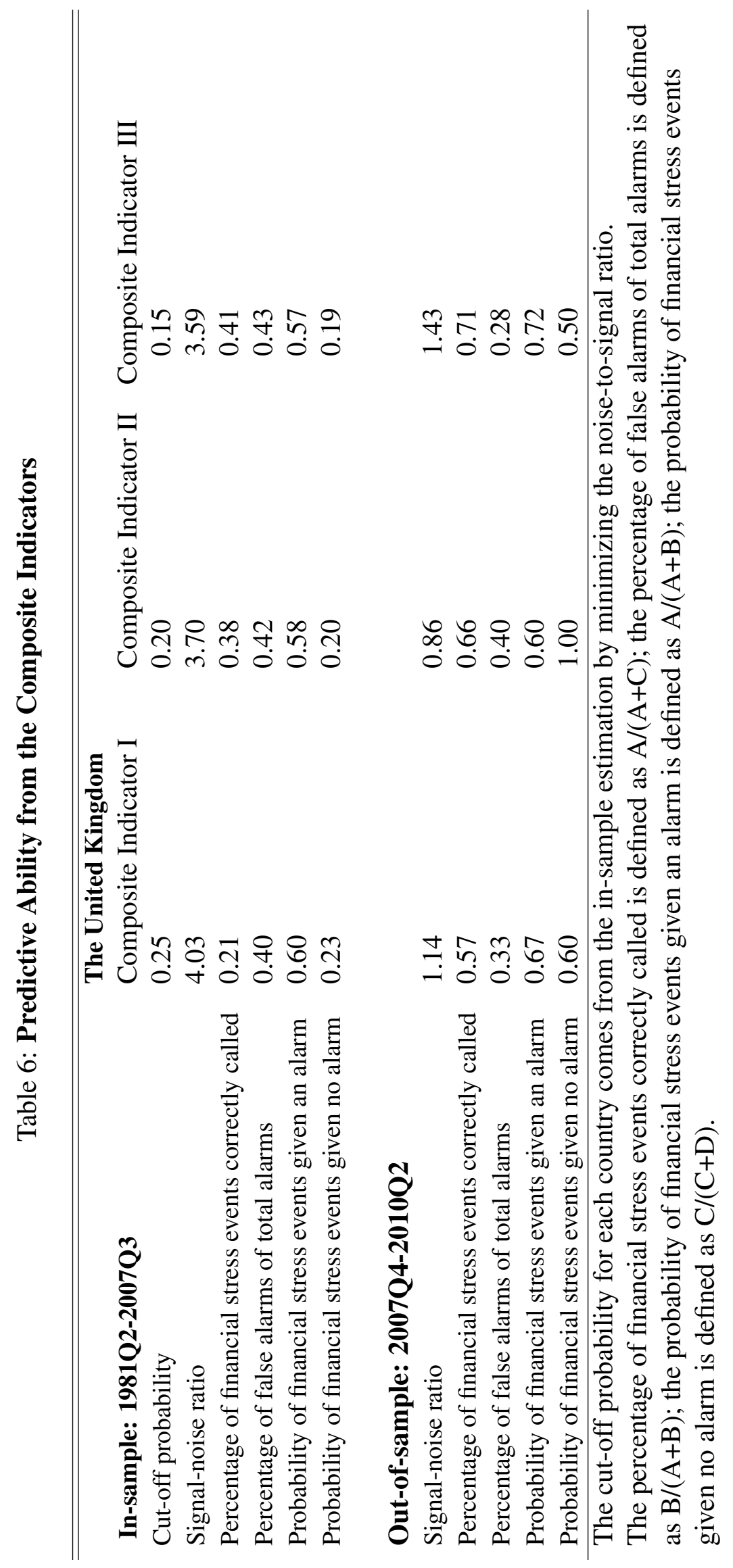




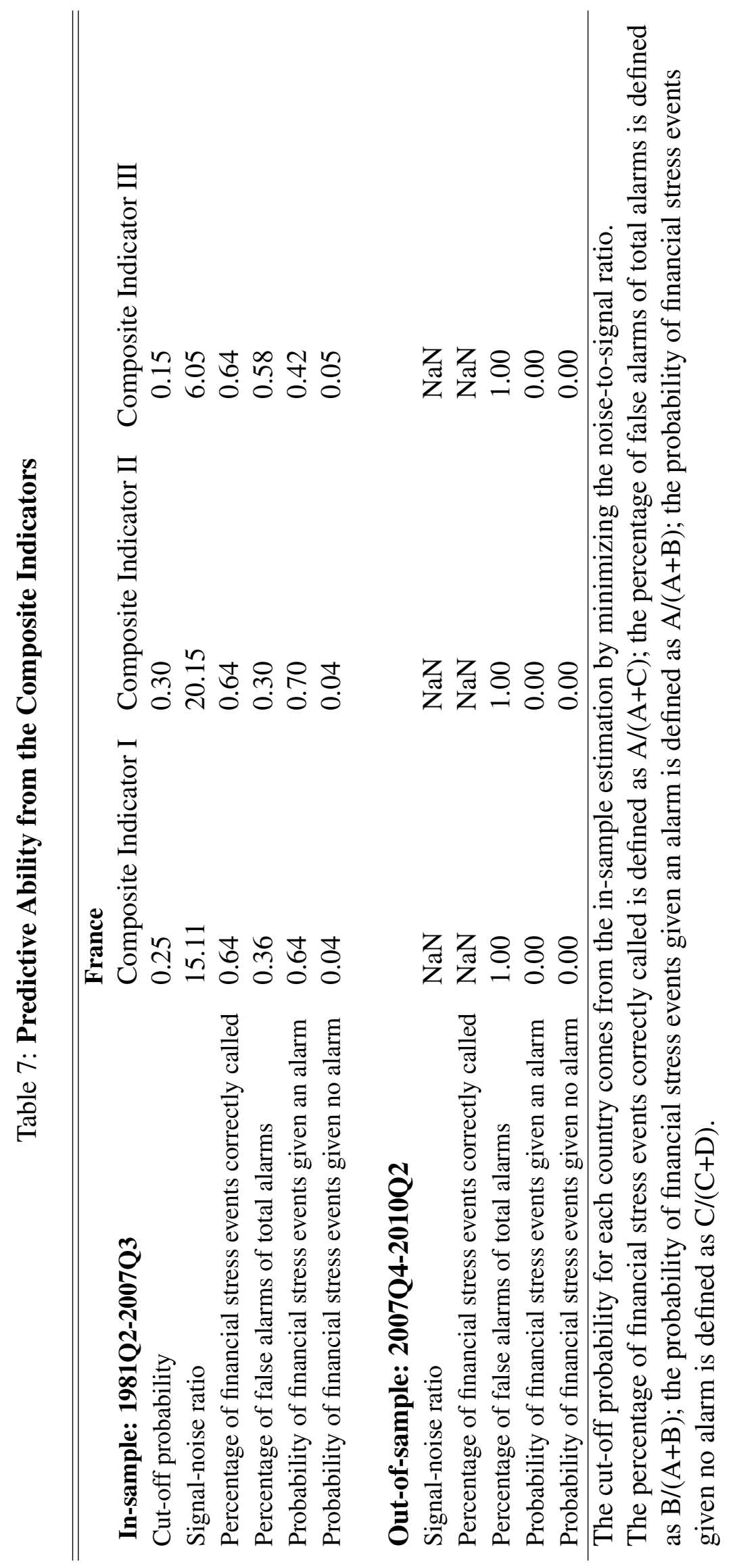




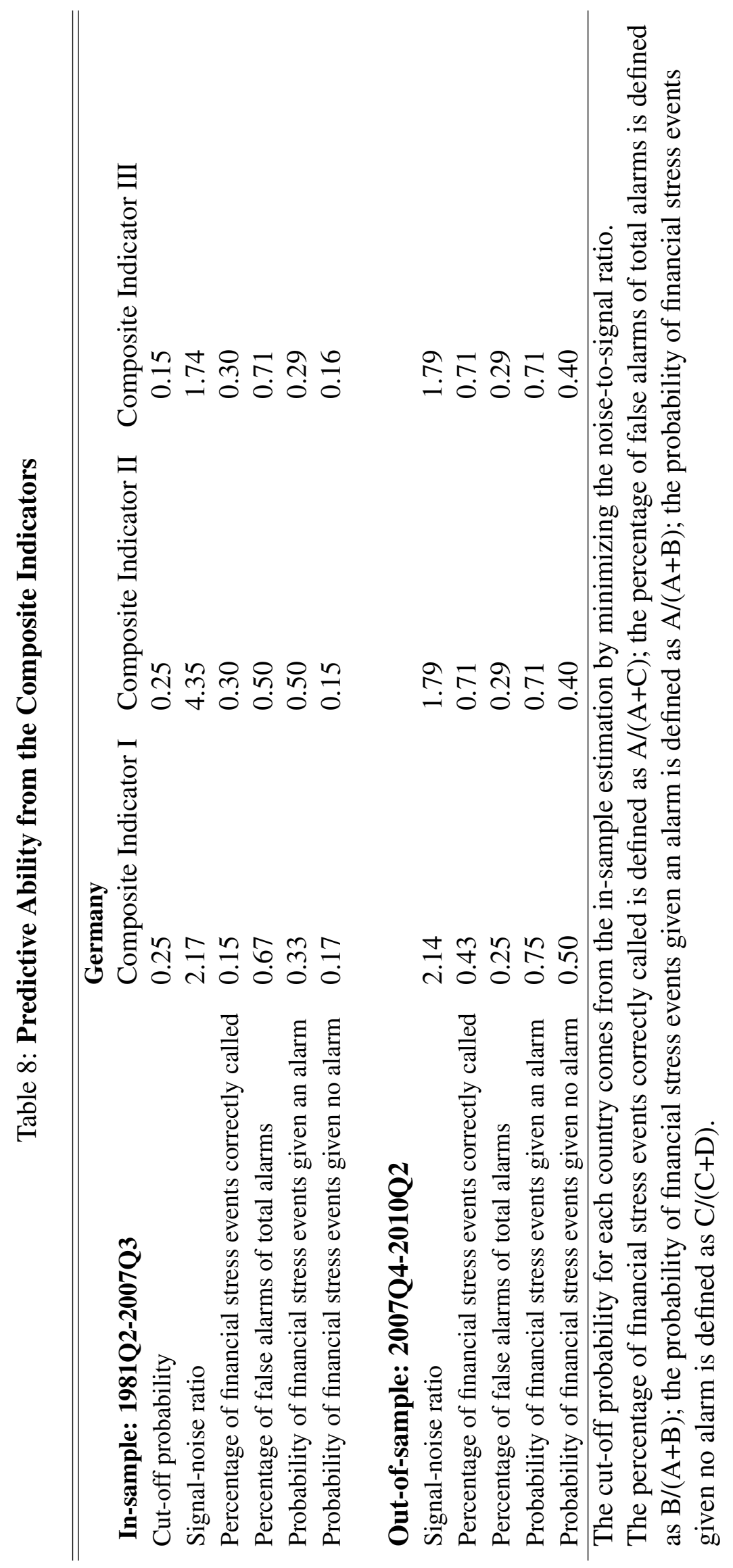




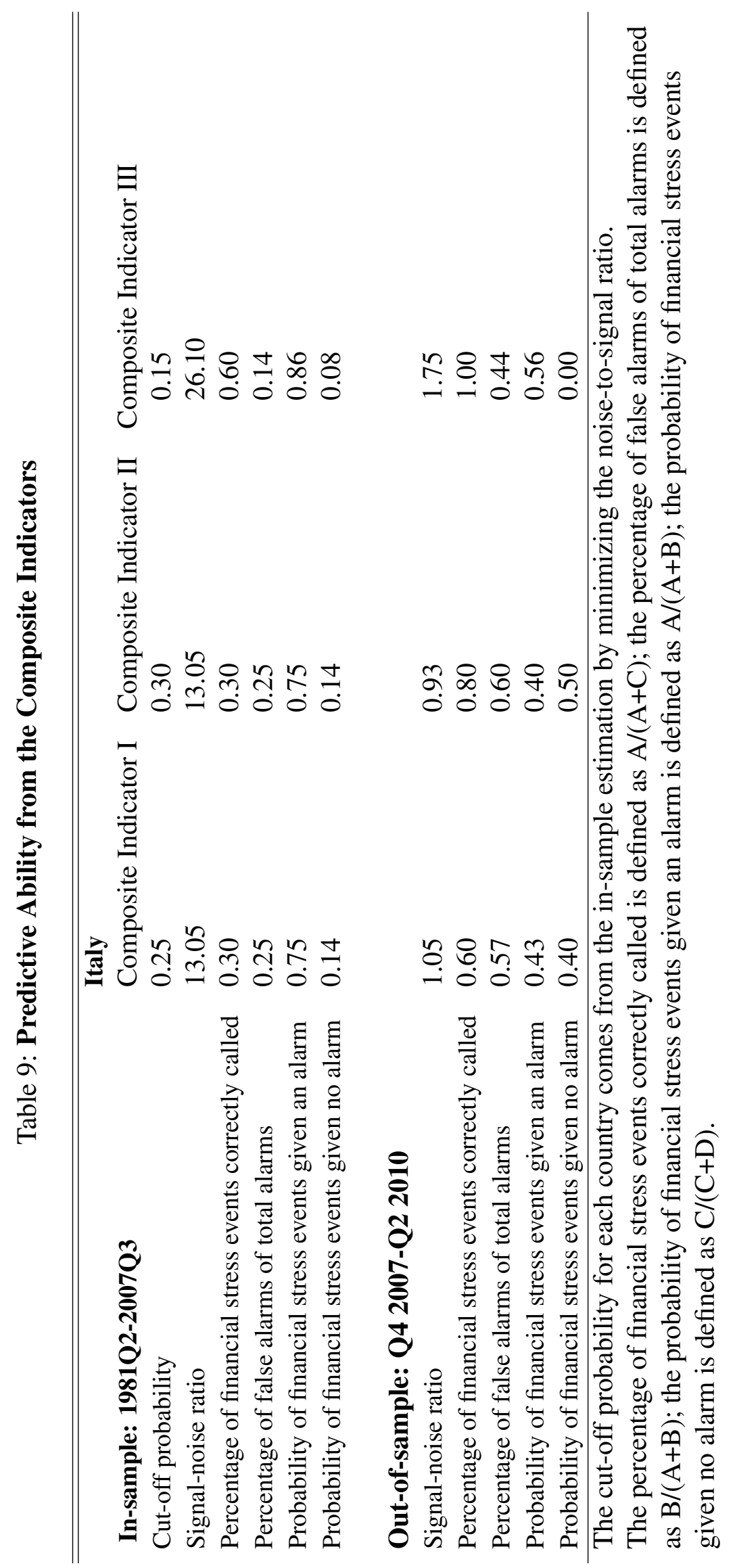




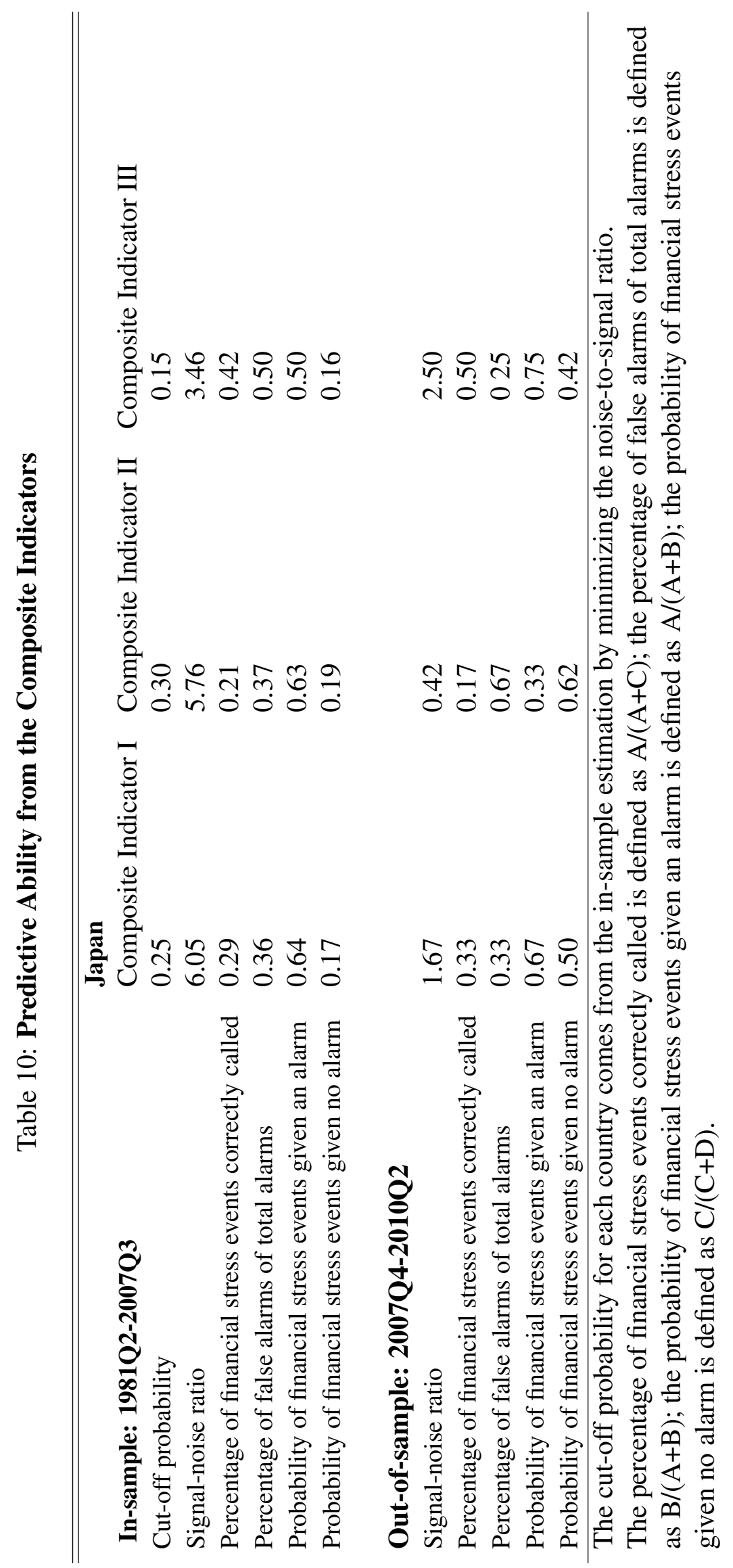




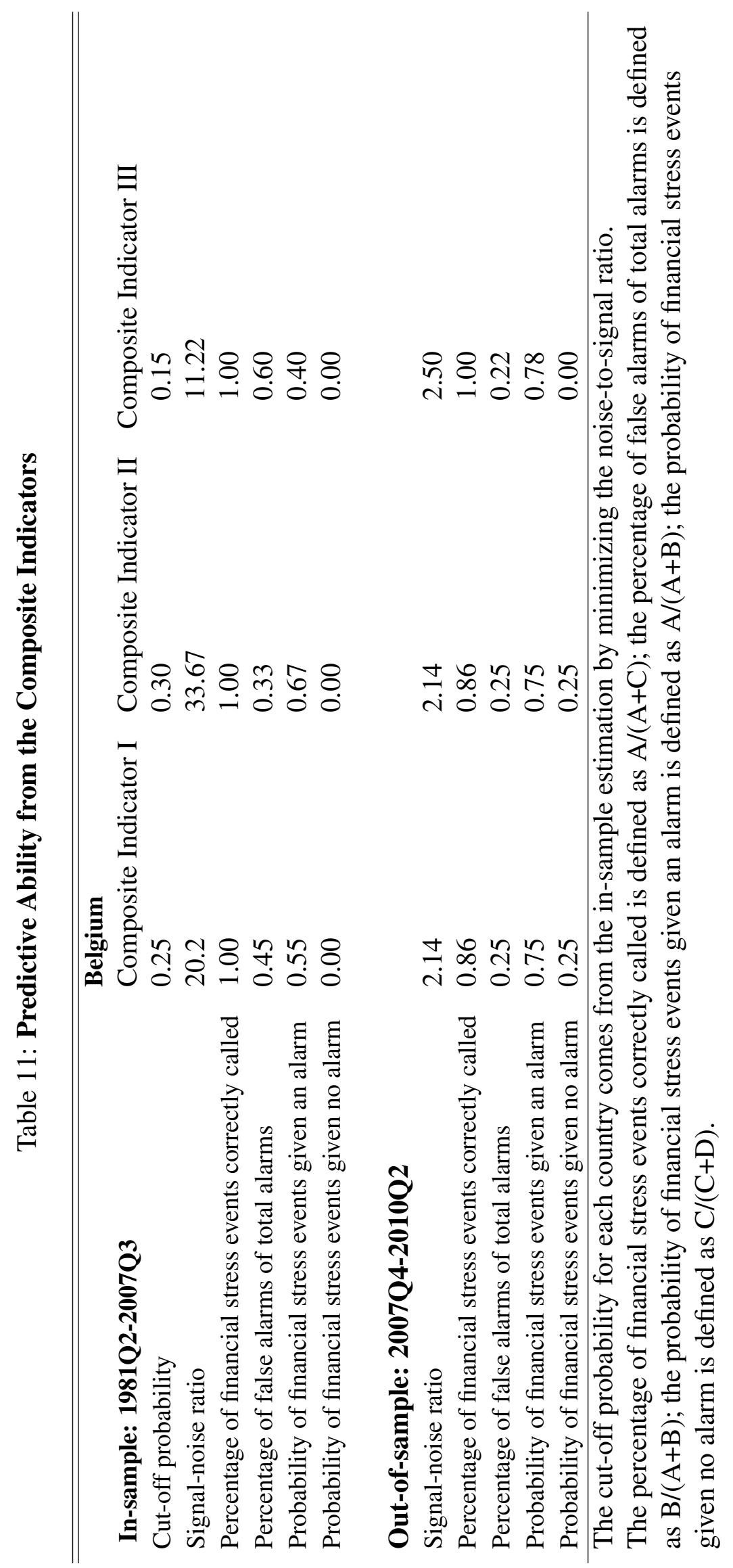




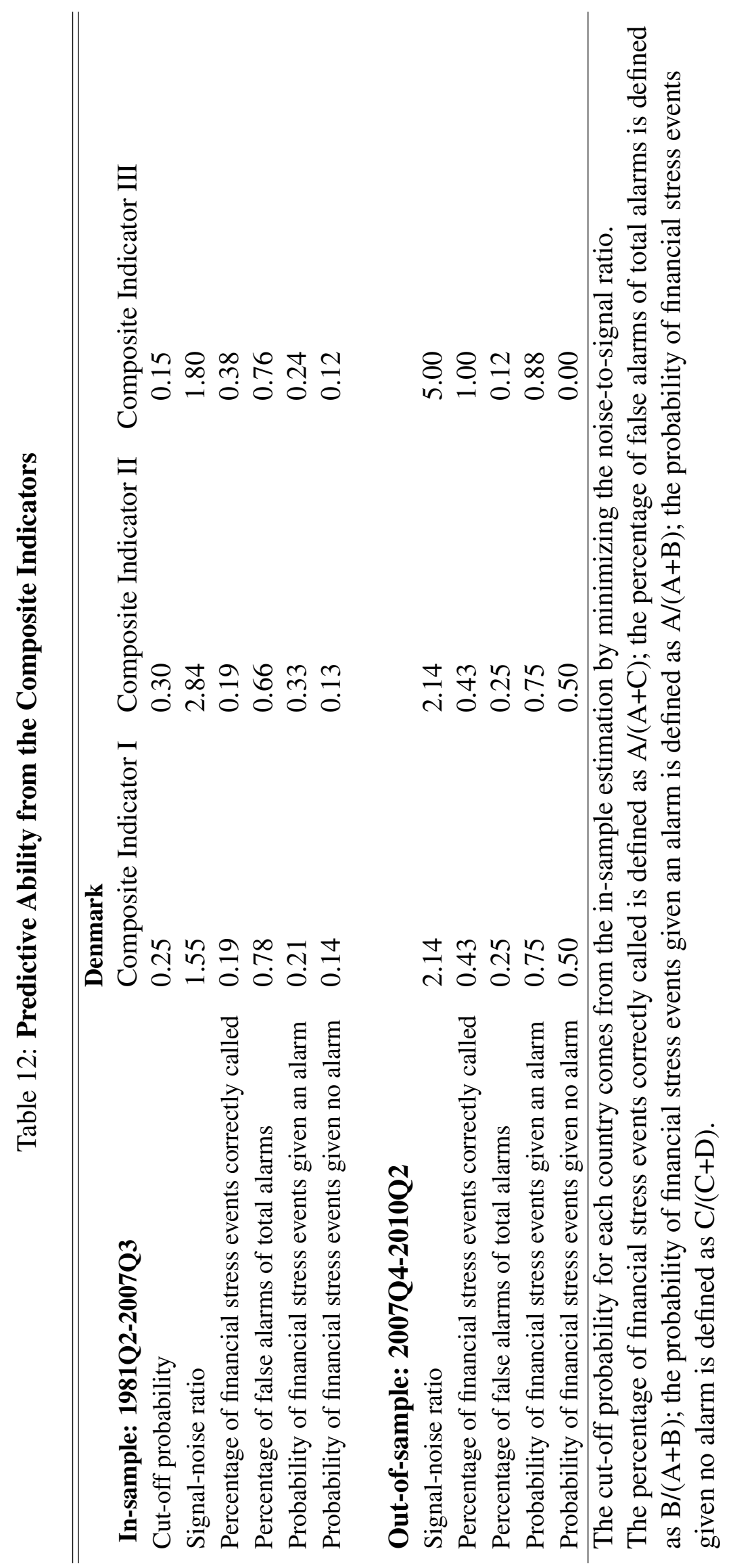




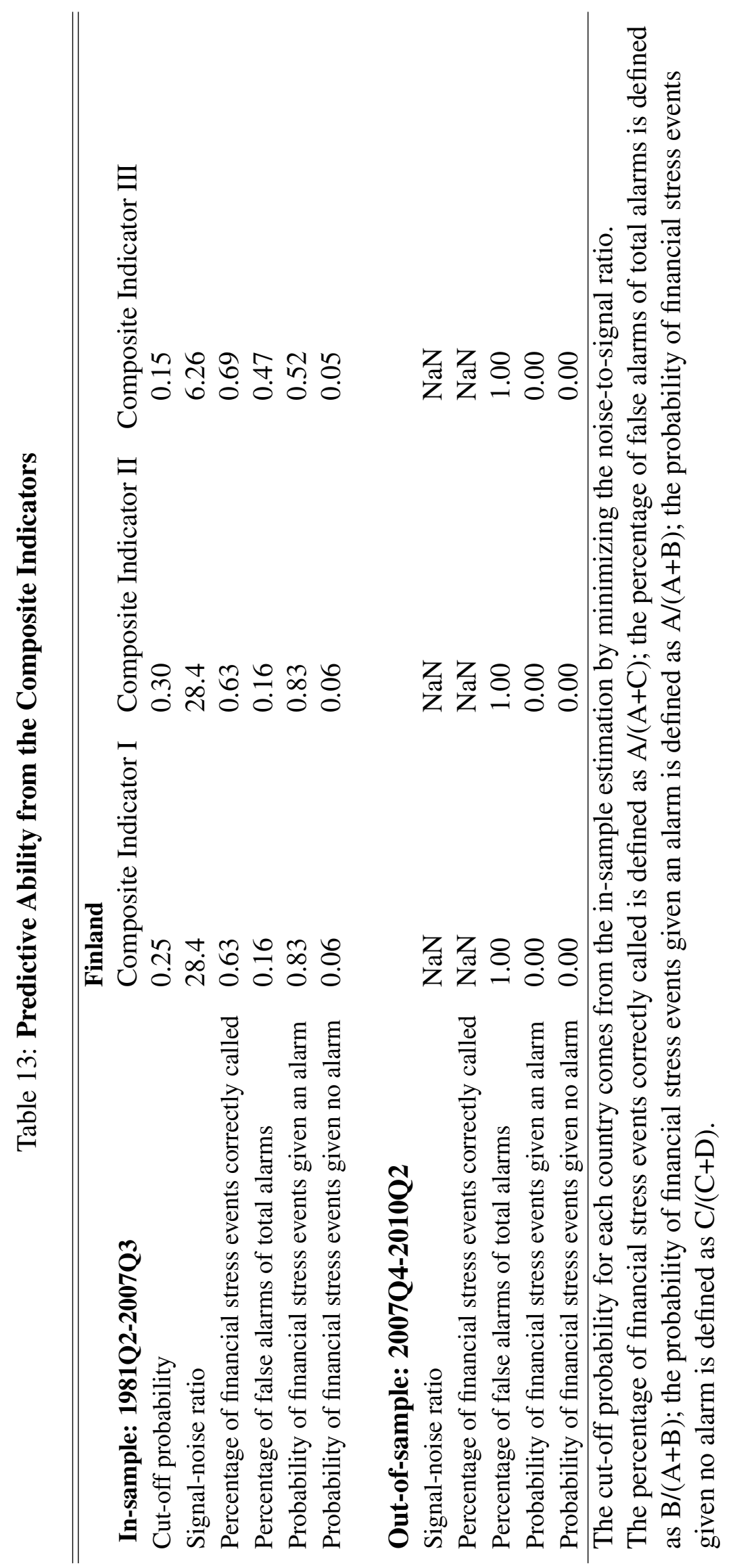




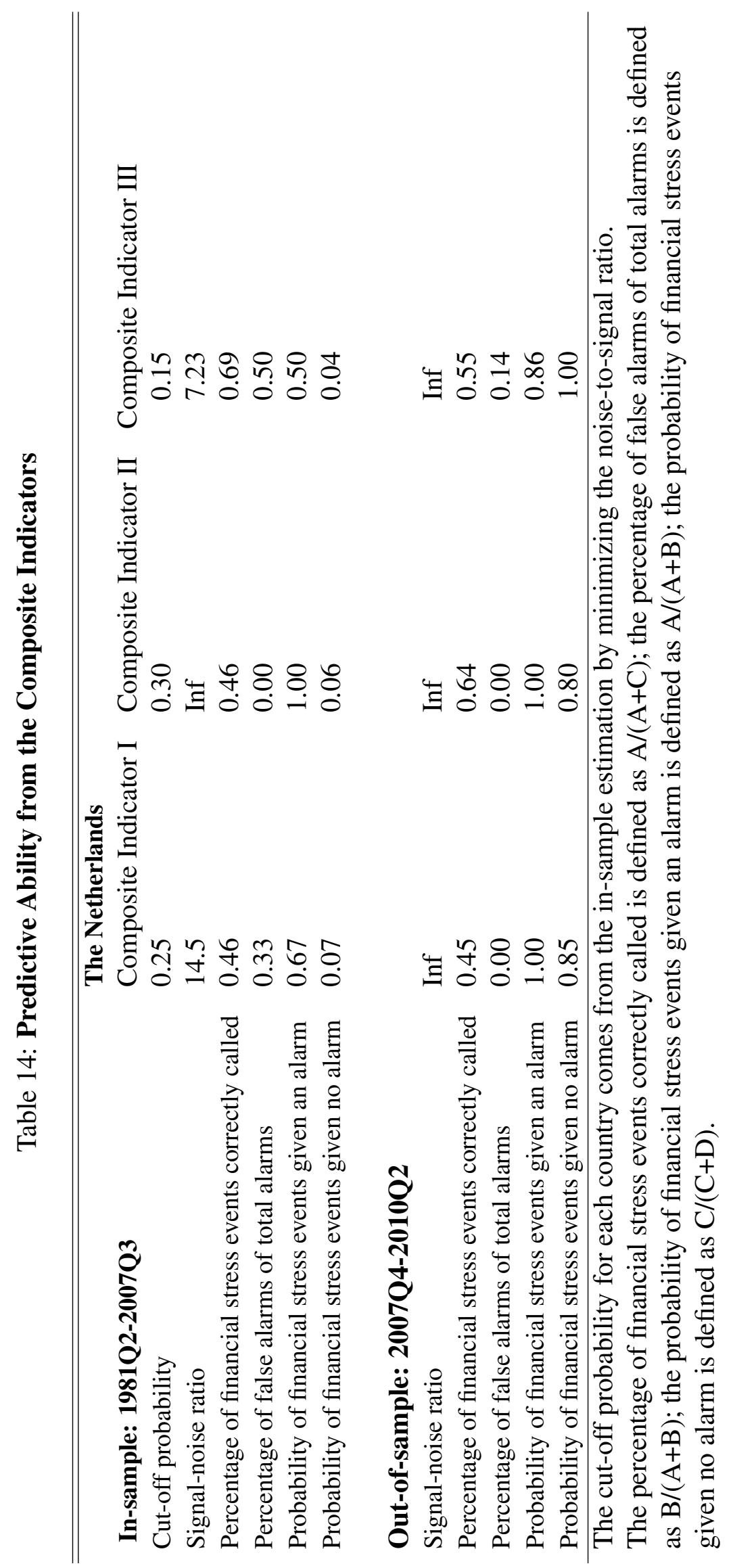




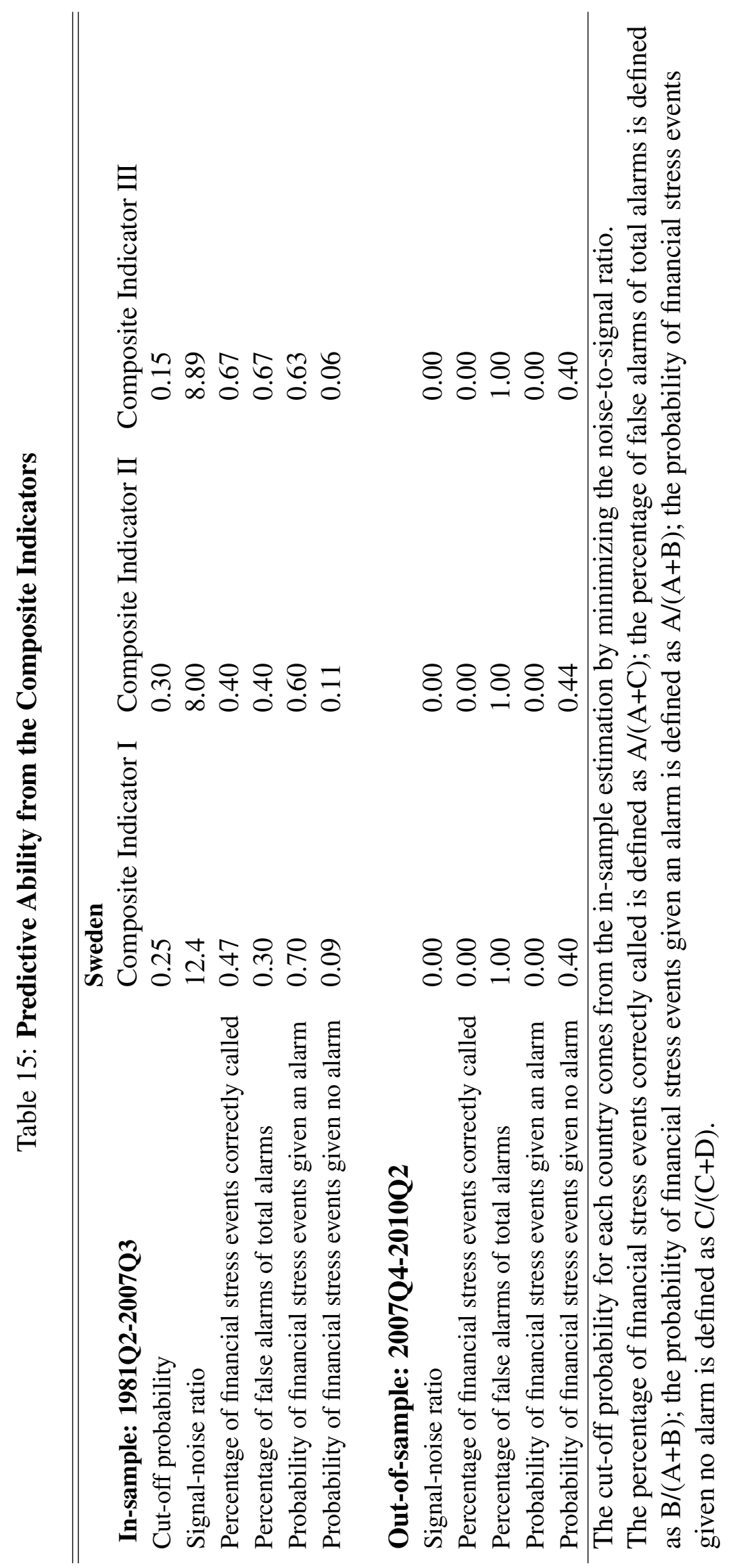




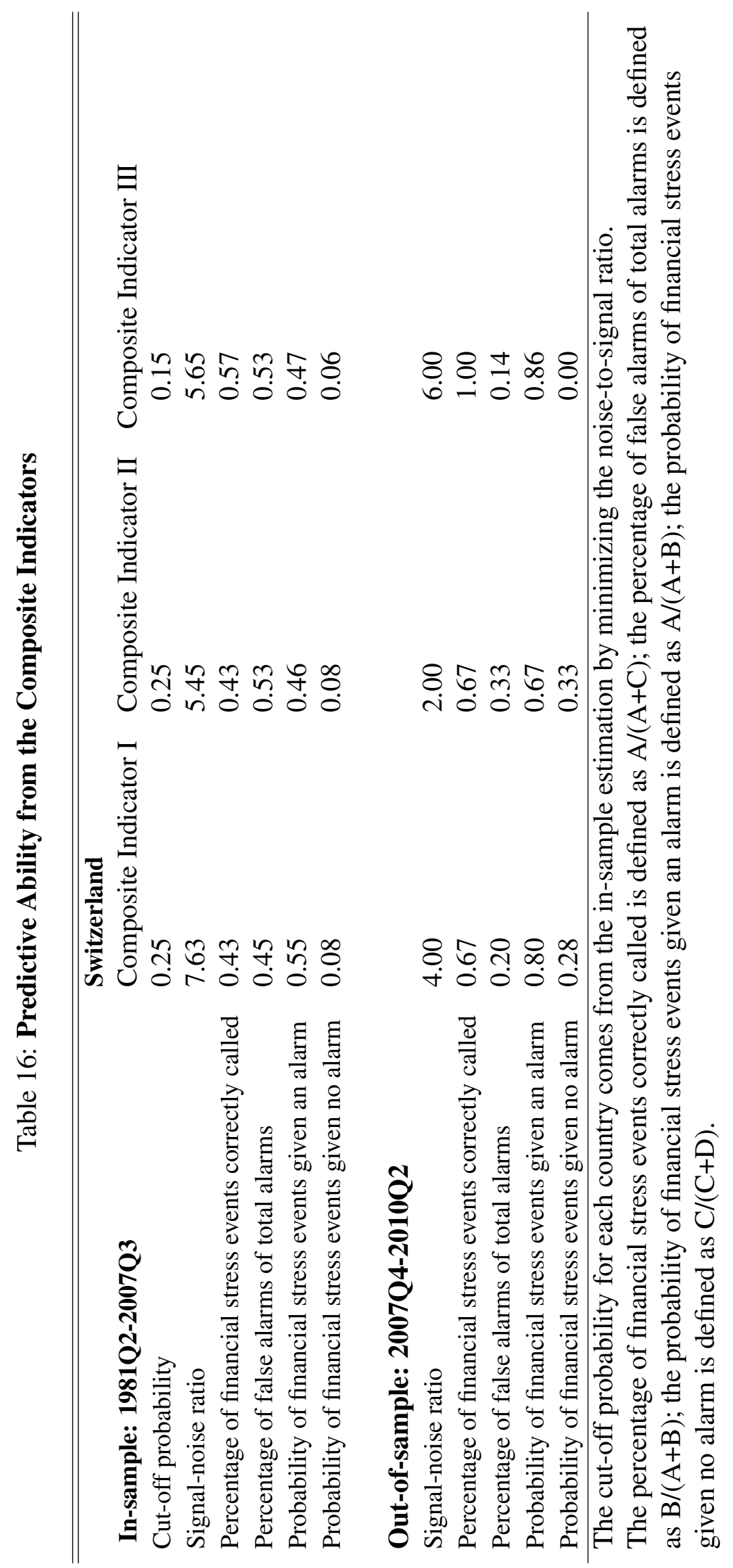




\section{Figure 1: Financial Stress Indexes for Selected Countries}
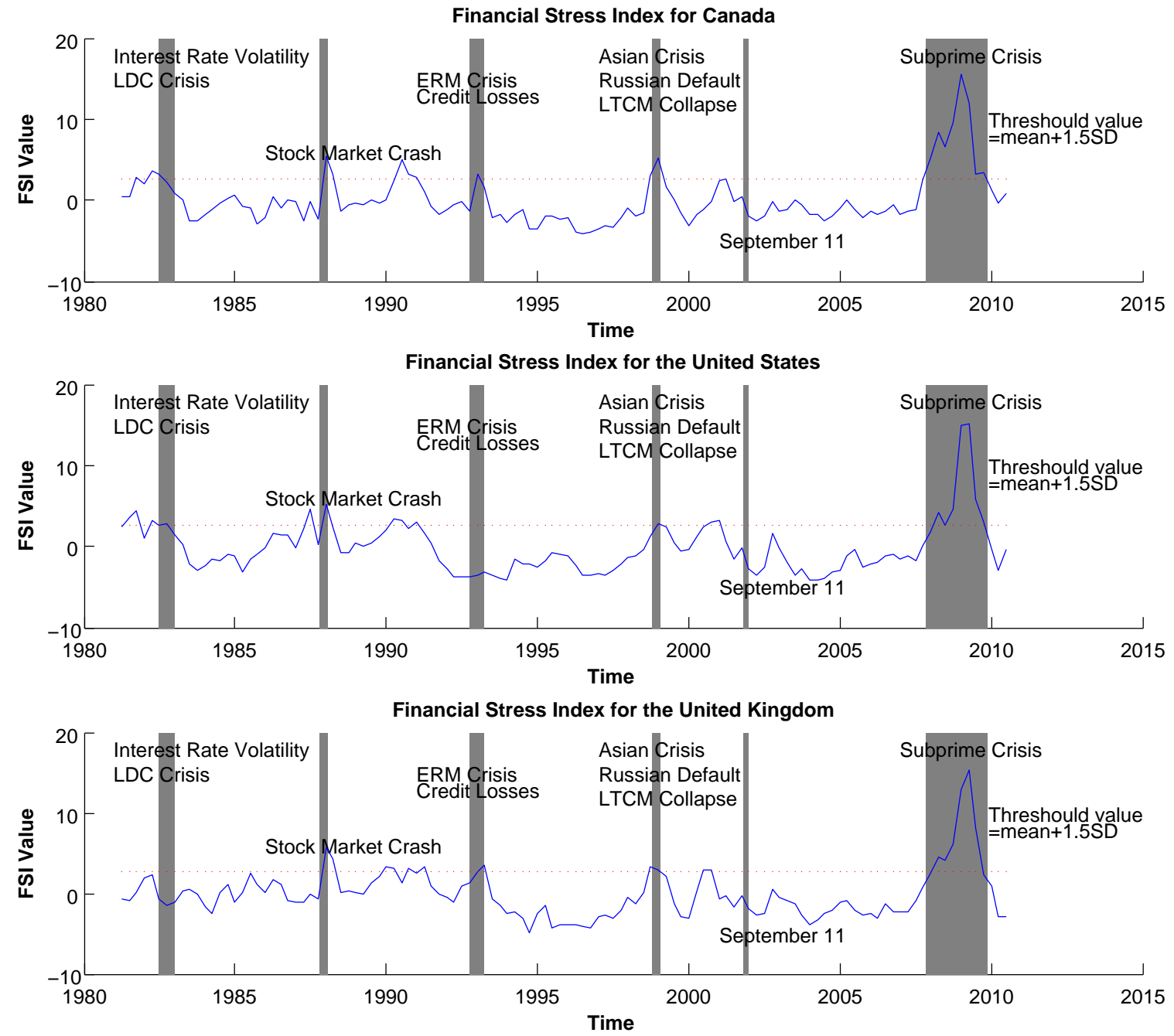

The shaded regions represent the time spans of financial crises. The solid lines are the FSIs, and the dashed lines are the thresholds. 


\section{Figure 2: Financial Stress Indexes for Selected Countries}
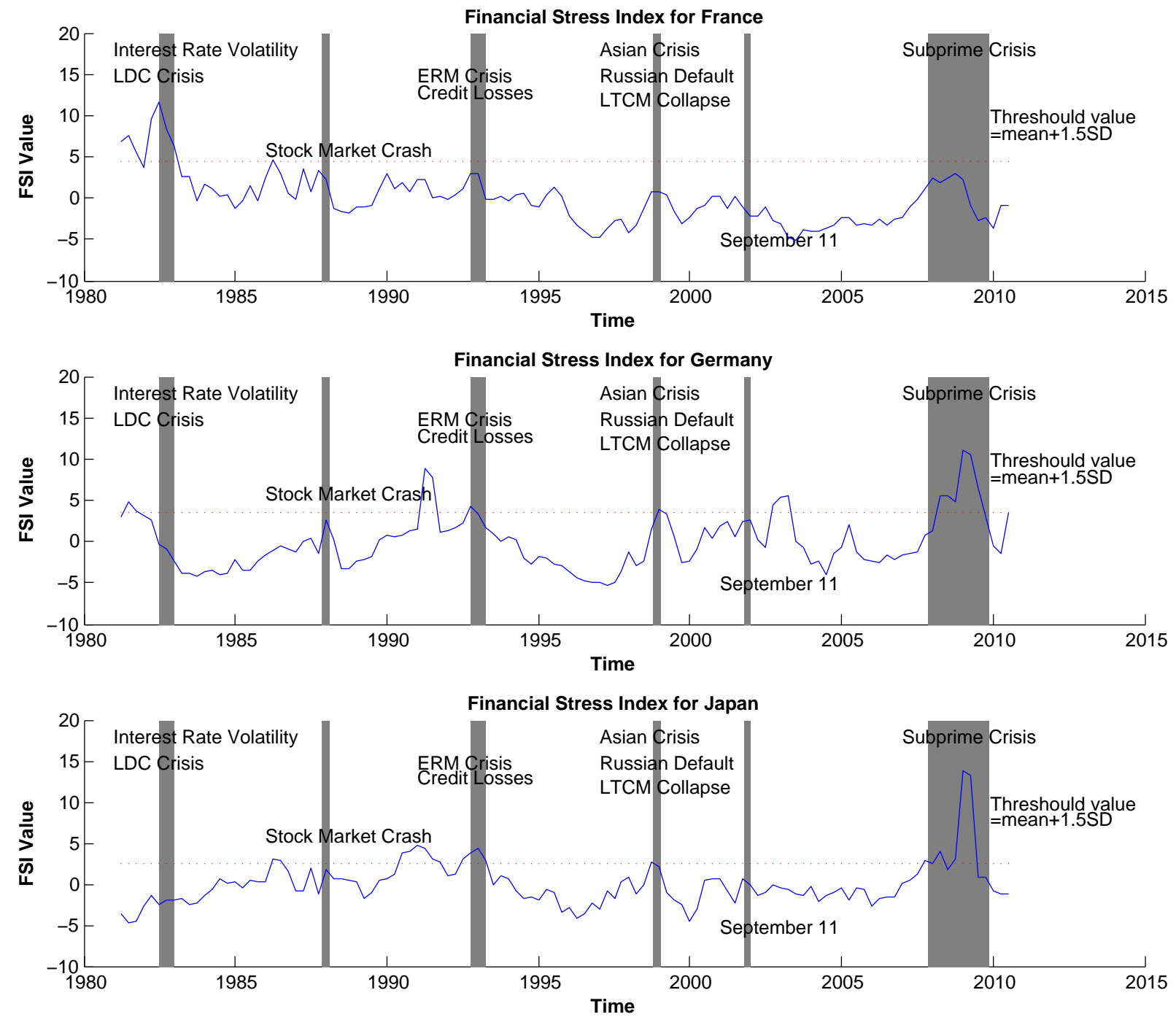

The shaded regions represent the time spans of financial crises. The solid lines are the FSIs, and the dashed lines are the thresholds. 


\section{Figure 3: Financial Stress Indexes for Selected Countries}
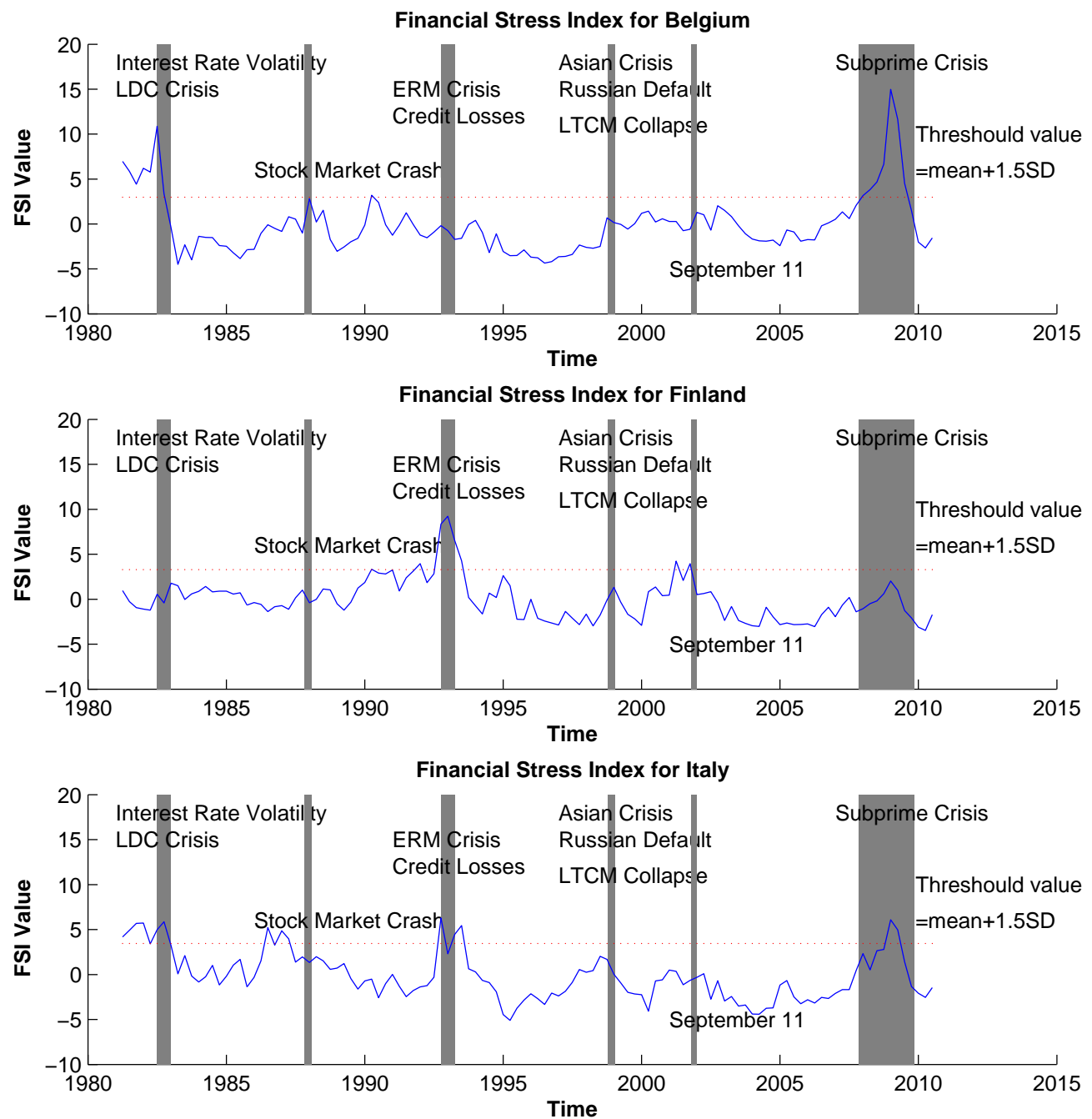

The shaded regions represent the time spans of financial crises. The solid lines are the FSIs, and the dashed lines are the thresholds. 


\section{Figure 4: Financial Stress Indexes for Selected Countries}
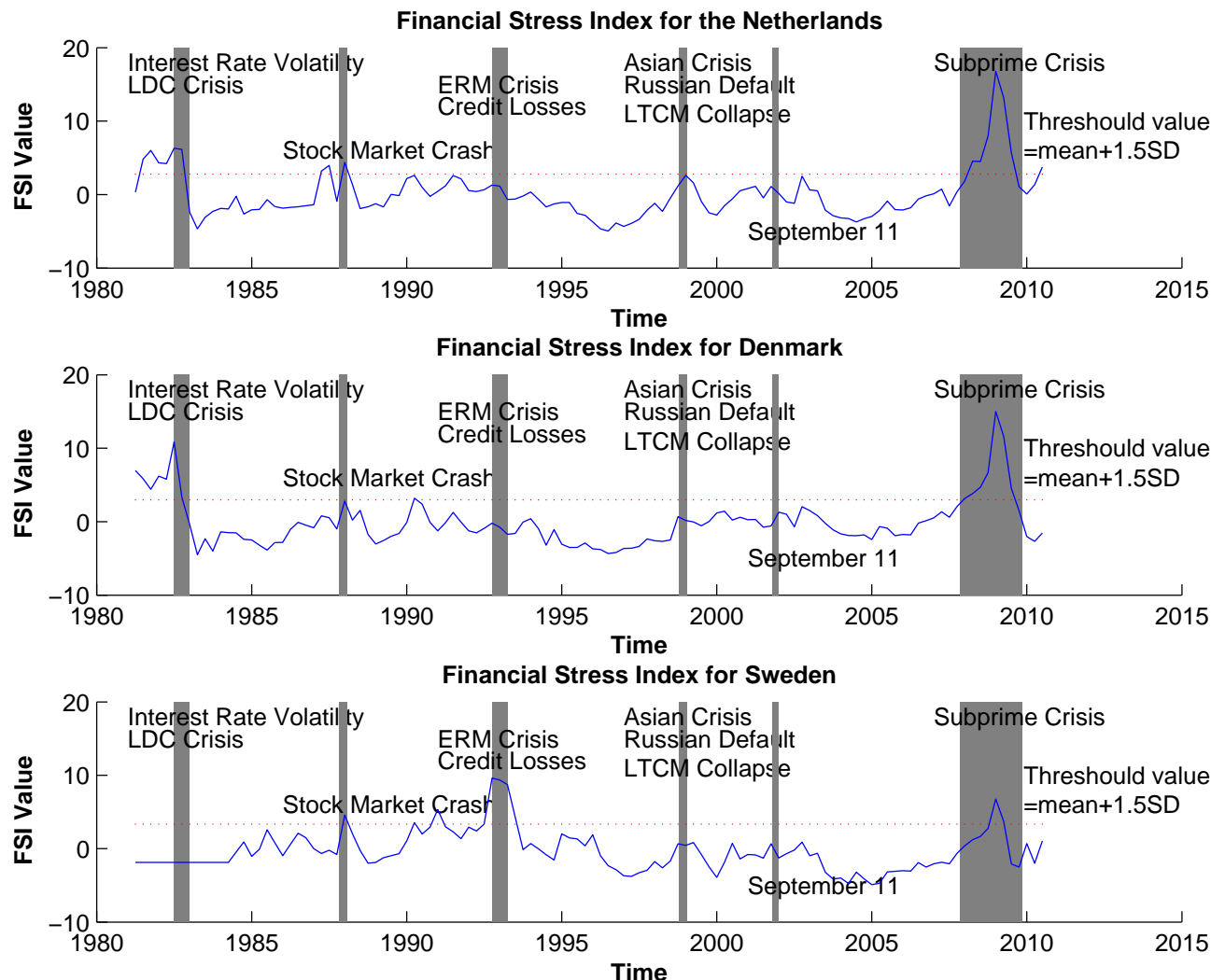

Financial Stress Index for Switzerland

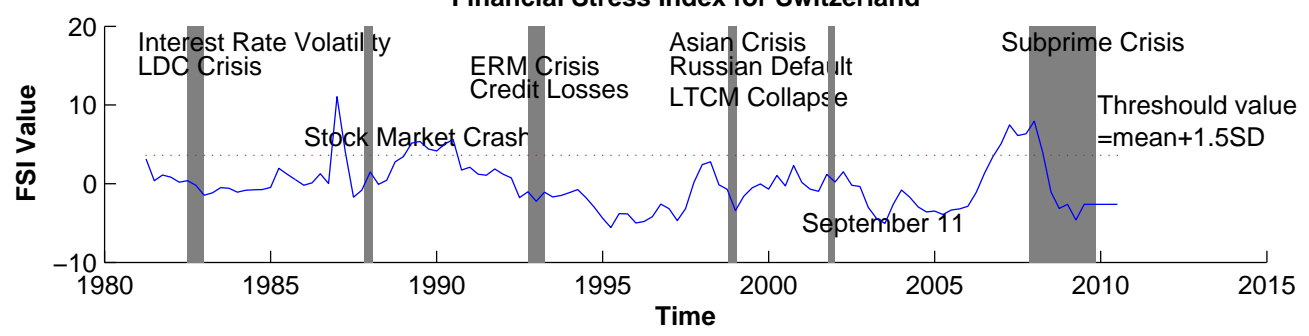

The shaded regions represent the time spans of financial crises. The solid lines are the FSIs, and the dashed lines are the thresholds. 
Figure 5: Probability Forecasts of Financial Stress Events for Selected Countries
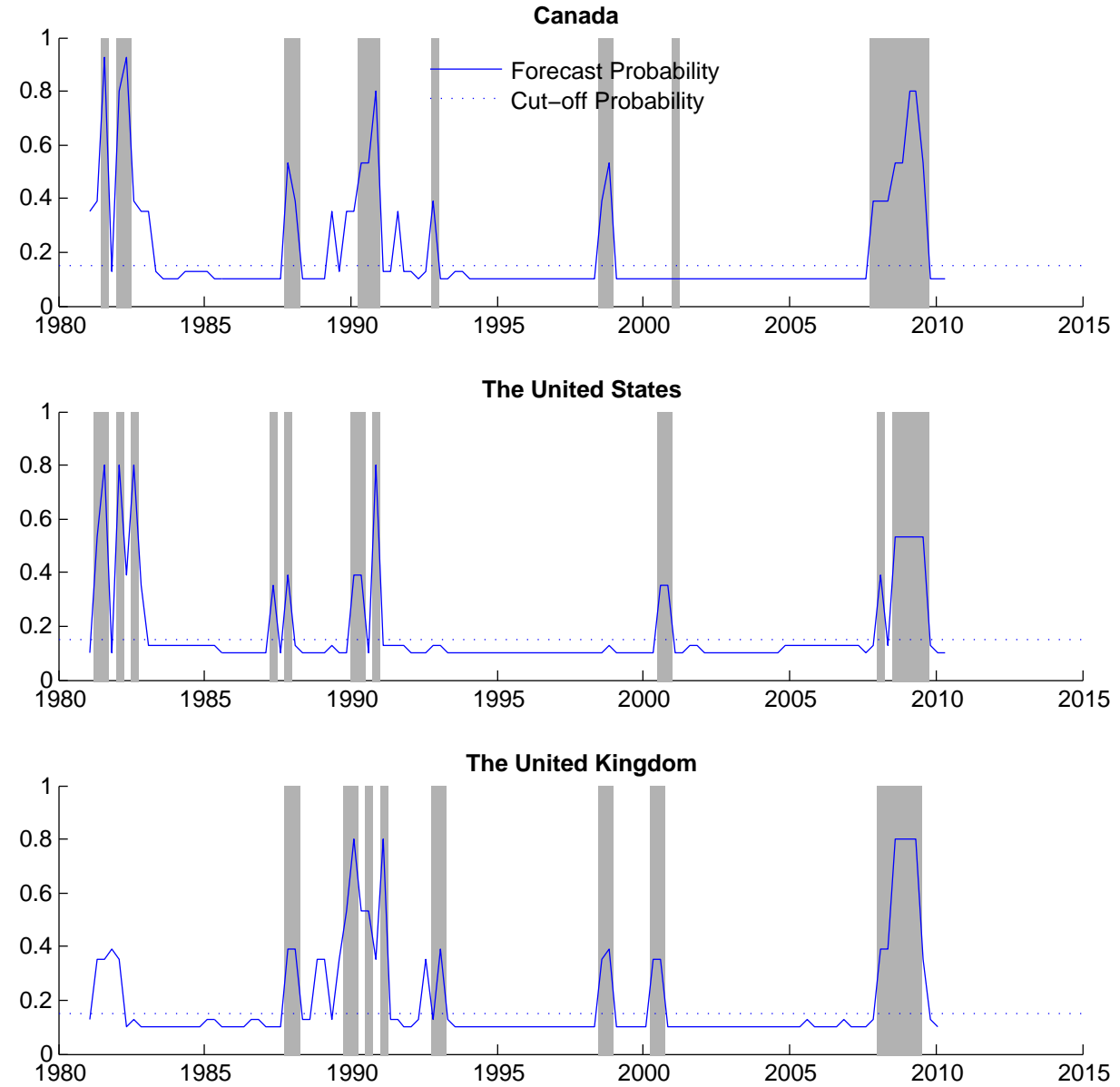

The shaded regions represent the time spans of financial stress events. The solid lines are the forecasted probabilities, and the dashed lines are the cut-off probabilities. 
Figure 6: Probability Forecasts of Financial Stress Events for Selected Countries
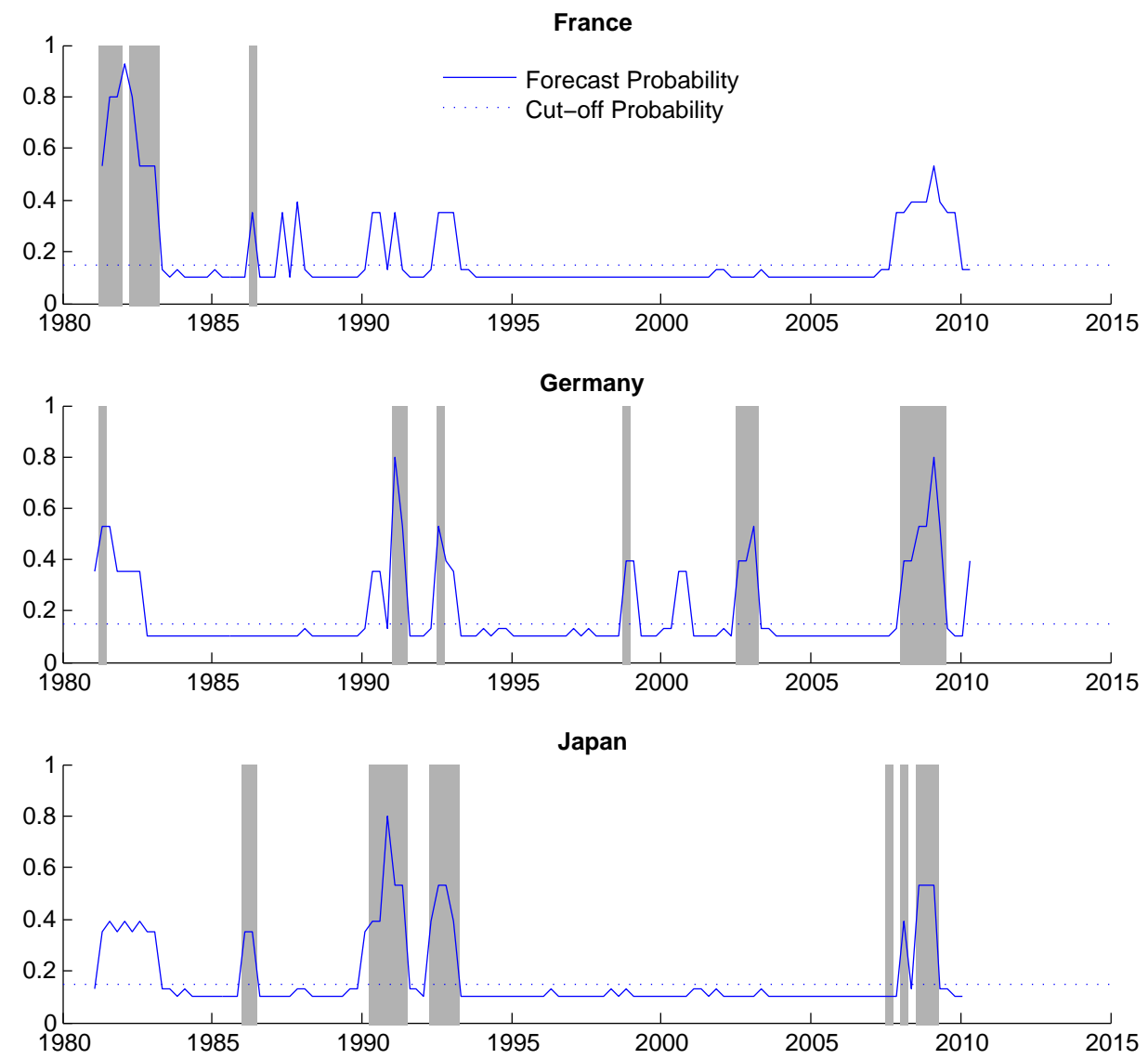

The shaded regions represent the time spans of financial stress events. The solid lines are the forecasted probabilities, and the dashed lines are the cut-off probabilities. 
Figure 7: Probability Forecasts of Financial Stress Events for Selected Countries
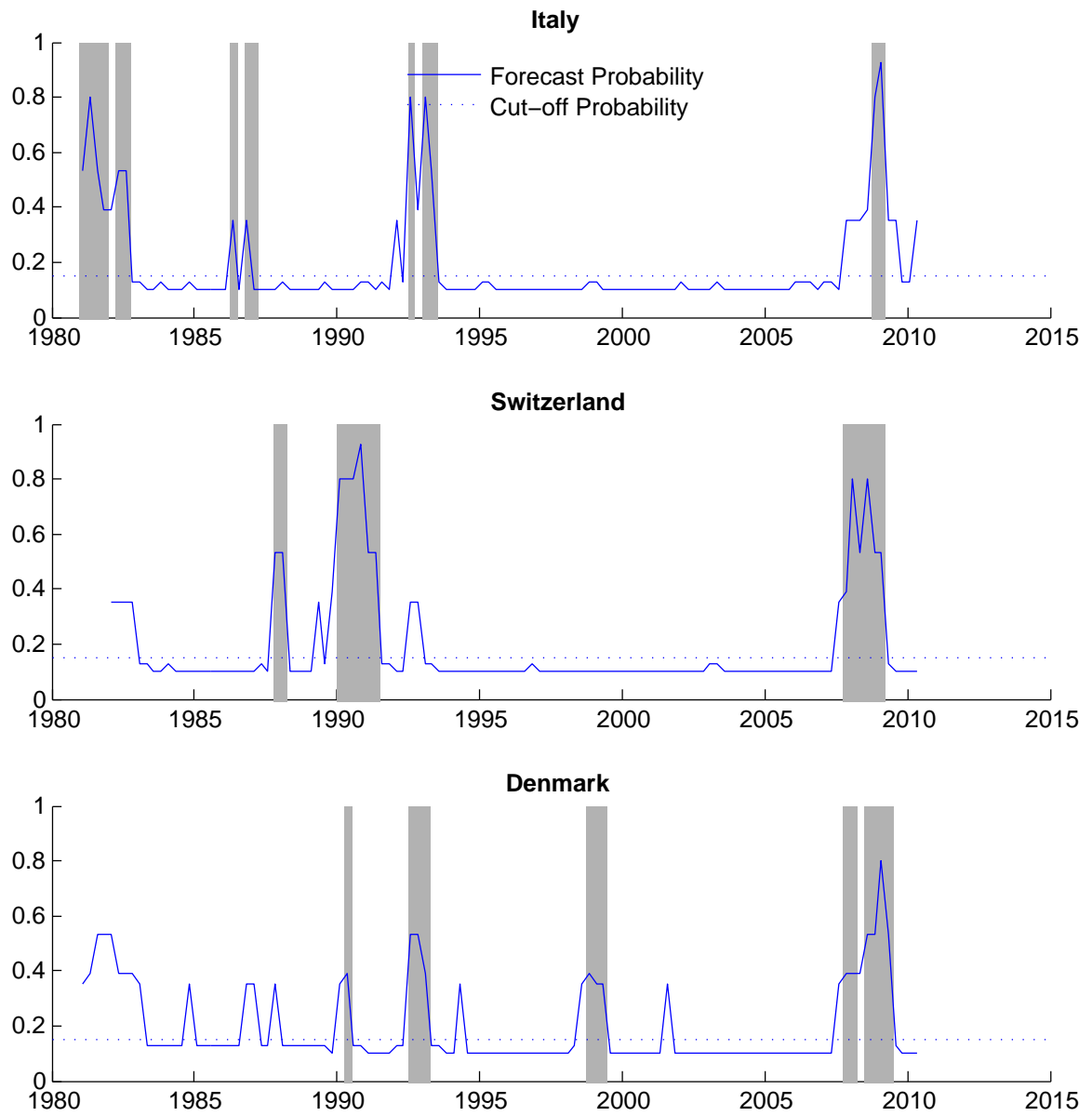

The shaded regions represent the time spans of financial stress events. The solid lines are the forecasted probabilities, and the dashed lines are the cut-off probabilities. 
Figure 8: Probability Forecasts of Financial Stress Events for Selected Countries
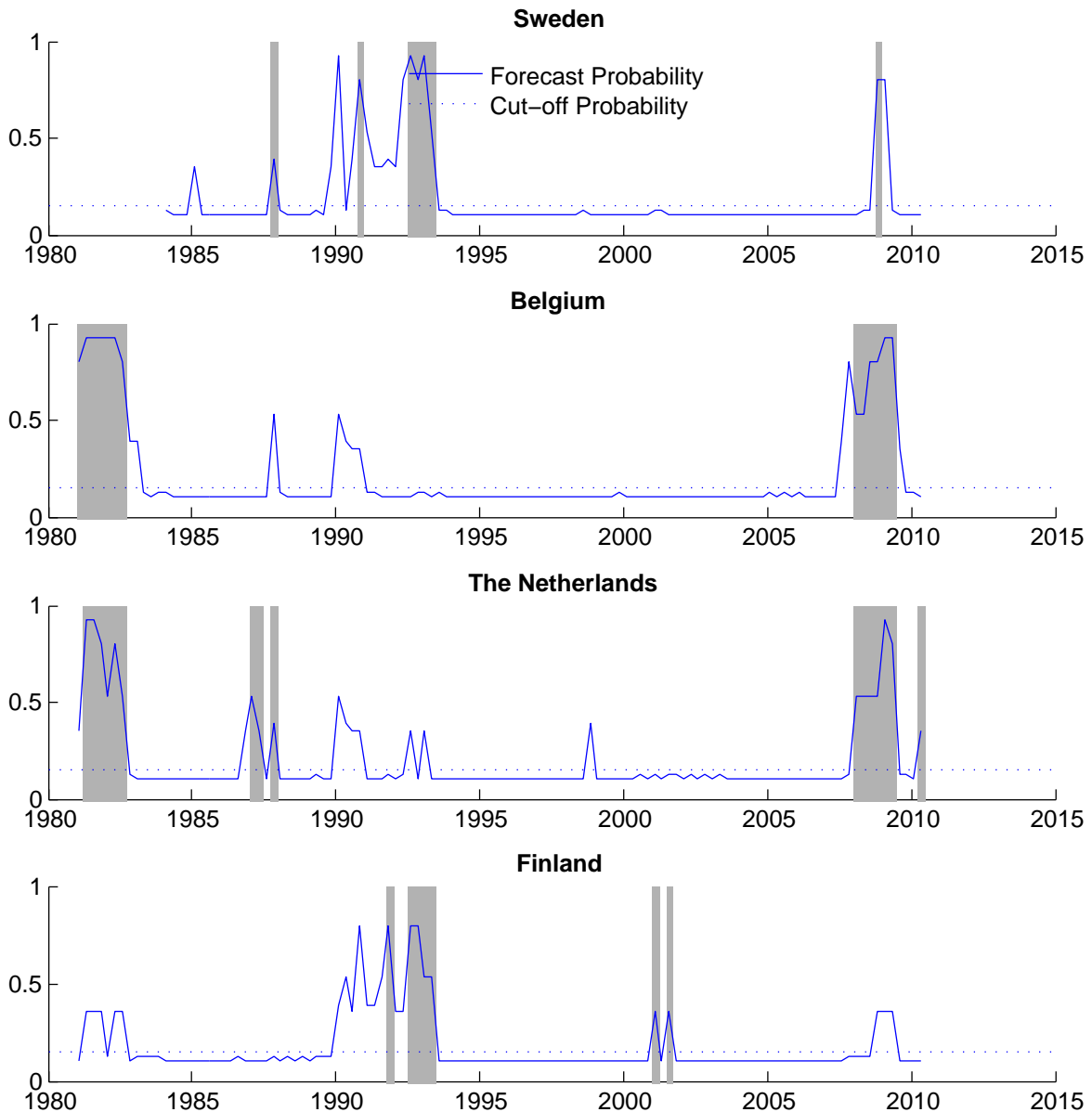

The shaded regions represent the time spans of financial stress events. The solid lines are the forecasted probabilities, and the dashed lines are the cut-off probabilities. 


\section{References}

[1] Bloom, N. (2009) “ The Impact of Uncertainty Shocks, ” Econometrica, Vol. 77, No 3, 623685.

[2] Borio, C. and M. Drehmann (2009) “ Assessing the Risk of Banking Crises ," Bank for International Settlements Quarterly Review, March 2009, 29-46.

[3] Cardarelli, R., S. Elekdag and S. Lall (2009) “Financial stress, downturns, and recoveries, ” IMF working paper, Wp 09/100.

[4] Christensen, I. and F. Li (2013) “A Semiparametric Early Warning Model of Financial Stress Events, " Bank of Canada working paper, Wp 2013-13.

[5] Davis, P. and D. Karim (2008) “ Comparing early warning systems for banking crises, ” Journal of Financial Stability (4), 2008, 89-120.

[6] Demirgüç-Kunt, A. and E. Detragiache (1998) “ The Determinants of Banking Crises in Developed and Developing Countries," IMF Staff Paper, Vol. 45, No.1, International Monetary Fund, Washington.

[7] Diebold, F. and G. Rudebusch (1989) “ Scoring the Leading Indicators, " Journal of Business, 1989, 62, 369-91.

[8] European Central Bank (2009) "Financial Stability Review December 2009, "Frankfurt/Main.

[9] Gneitinga, T., and R. Ranjanb (2011) “Comparing Density Forecasts Using Threshold- and Quantile-Weighted Scoring Rules, " Journal of Business and Economic Statistics, Volume 29, Issue 3, 411-422. 
[10] Hakkio, C. and W. Keeton (2009) "Financial Stress: What is it, How Can It Be Measured, and Why Does It Matter?" Federal Reserve Bank of Kansas City-Economic Review, Second Quarter, 5-50.

[11] Illing, M., and Y. Liu (2006) "Measuring Financial Stress in a Developed Country: An Application to Canada, " Journal of Financial Stability 2 (3), 243-65.

[12] Kaminsky, G. (1998) “Currency and Banking Crises: the Early Warning of Distress, ” IMF Working Paper No. 178. Interantional Monetary Fund.

[13] Kaminsky G., Lizondo S. and C. Reinhart (1998) “Leading Indicators of Currency Crises,” International Monetary Fund Staff Papers 1998(45), 1-48.

[14] Misina, M. and G. Tkacz (2009) “Credit, Asset Prices, and Financial Stress, ” International Journal of Central Banking 5(4), 95-122.

[15] Slingenberg, J.W. and J. de Haan (2011) "Forecasting Financial Stress, "DNB Working Paper, No. 292/April 2011. 